\title{
Terrestrial Structure from Motion Photogrammetry for Deriving Forest Inventory Data
}

\author{
Livia Piermattei ${ }^{1,2, *}$, Wilfried Karel ${ }^{1}\left(\mathbb{D}\right.$, Di Wang ${ }^{1,3}{ }^{-}$, Martin Wieser ${ }^{1}$, Martin Mokroš ${ }^{4}{ }^{\oplus}$,

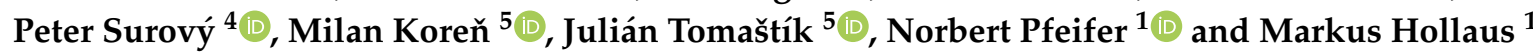 \\ 1 Department of Geodesy and Geoinformation, TU Wien, 1040 Vienna, Austria; \\ Wilfried.Karel@geo.tuwien.ac.at (W.K.); di.wang@aalto.fi (D.W.); Martin.Wieser@geo.tuwien.ac.at (M.W.); \\ Norbert.Pfeifer@geo.tuwien.ac.at (N.P.); Markus.Hollaus@geo.tuwien.ac.at (M.H.) \\ 2 Physical Geography, Catholic University of Eichstätt-Ingolstadt, 85072 Eichstätt, Germany \\ 3 Department of Built Environment, Aalto University, 00076 Aalto, Finland \\ 4 Faculty of Forestry and Wood Sciences, Czech University of Life Sciences Prague, \\ 16500 Praha 6, Suchodol, Czech Republic; mokros@fld.czu.cz (M.M.); surovy@fld.czu.cz (P.S.) \\ 5 Department of Forest management and Geodesy, Faculty of Forestry, Technical University in Zvolen, \\ 96053 Zvolen, Slovakia; milan.koren@tuzvo.sk (M.K.); julian.tomastik@tuzvo.sk (J.T.) \\ * Correspondence: livia.piermattei@geo.tuwien.ac.at; Tel.: +43-(1)58801-12257
}

Received: 12 March 2019; Accepted: 18 April 2019; Published: 20 April 2019

\begin{abstract}
The measurements of tree attributes required for forest monitoring and management planning, e.g., National Forest Inventories, are derived by rather time-consuming field measurements on sample plots, using calipers and measurement tapes. Therefore, forest managers and researchers are looking for alternative methods. Currently, terrestrial laser scanning (TLS) is the remote sensing method that provides the most accurate point clouds at the plot-level to derive these attributes from. However, the demand for even more efficient and effective solutions triggers further developments to lower the acquisition time, costs, and the expertise needed to acquire and process 3D point clouds, while maintaining the quality of extracted tree parameters. In this context, photogrammetry is considered a potential solution. Despite a variety of studies, much uncertainty still exists about the quality of photogrammetry-based methods for deriving plot-level forest attributes in natural forests. Therefore, the overall goal of this study is to evaluate the competitiveness of terrestrial photogrammetry based on structure from motion (SfM) and dense image matching for deriving tree positions, diameters at breast height (DBHs), and stem curves of forest plots by means of a consumer grade camera. We define an image capture method and we assess the accuracy of the photogrammetric results on four forest plots located in Austria and Slovakia, two in each country, selected to cover a wide range of conditions such as terrain slope, undergrowth vegetation, and tree density, age, and species. For each forest plot, the reference data of the forest parameters were obtained by conducting field surveys and TLS measurements almost simultaneously with the photogrammetric acquisitions. The TLS data were also used to estimate the accuracy of the photogrammetric ground height, which is a necessary product to derive DBHs and tree heights. For each plot, we automatically derived tree counts, tree positions, DBHs, and part of the stem curve from both TLS and SfM using a software developed at TU Wien (Forest Analysis and Inventory Tool, FAIT), and the results were compared. The images were oriented with errors of a few millimetres only, according to checkpoint residuals. The automatic tree detection rate for the SfM reconstruction ranges between $65 \%$ and $98 \%$, where the missing trees have average DBHs of less than $12 \mathrm{~cm}$. For each plot, the mean error of SfM and TLS DBH estimates is $-1.13 \mathrm{~cm}$ and $-0.77 \mathrm{~cm}$ with respect to the caliper measurements. The resulting stem curves show that the mean differences between SfM and TLS stem diameters is at maximum $-2.45 \mathrm{~cm}$ up to $3 \mathrm{~m}$ above ground, which increases to almost $+4 \mathrm{~cm}$ for higher elevations. This study shows that with the adopted image capture method, terrestrial SfM photogrammetry, is an accurate solution to support forest inventory for estimating the number of trees and their location, the DBHs and stem curve up to $3 \mathrm{~m}$ above ground.
\end{abstract}


Keywords: terrestrial photogrammetry; plot-based forest inventory; structure from motion; terrestrial laser scanning; diameter at breast height

\section{Introduction}

The assessment of spatial and temporal change of forest resources is an essential component of forest management and forest monitoring programs, and it is periodically realized with updated inventories [1]. The levels and periodicities of forest inventory update, as well as the survey methods and technologies applied, vary in each country according to the intended use, inherent costs, timelines, and desired accuracy of the inventory. Plot-scale forest measurements have been the basis for forest inventory for over 200 years [2,3]. In forest inventory, a plot is a designated area (usually of circular shape with a radius of several meters) in which measurements of forest variables are collected. These measurements are essential to obtaining comprehensive and detailed up-to-date information about the status of forest resources, but a sufficient number of sample plots need to be established to systematically characterize the forest variability $[4,5]$.

In the context of operational forest inventory and management, the most important plot-scale forest-related parameters are the number of trees, tree density, tree height, and the diameter-at-breast height (DBH, measured $1.30 \mathrm{~m}$ above ground). Conventionally, these are measured using clinometers (for the height), calipers and diameter tapes (for the DBH), depending on the thickness of the stem. This traditional approach to collect the parameters manually is called field inventory in forestry. Field inventory is still an important method that is widely used in the areas of forest research, monitoring and management, which rely on knowledge of forest structure, distribution and dynamics over time [6]. However, plot-based field inventory is labour-intensive, time- and money-consuming, and lacks the capacity to measure the forest structure beyond the sample plots and the tree shapes beyond the individual tree level. Hence, these used to be interpolated over the area of interest [6]. Furthermore, tree height and DBH measurements are subject to errors that are small only for experienced observers [7]. To overcome these deficiencies, the combination of field inventory and remote sensing technologies has been widely acknowledged in the last few decades. In most cases, field sampling measures are used either to calibrate or to validate forest variables derived from remote sensing data.

LiDAR (Light Detection and Ranging) technology is currently attracting the attention of the forestry community as a rapid and efficient tool for forest inventories [8]. While airborne LiDAR (airborne laser scanning, ALS) features the ability to cover large areas (up to regional level) and to penetrate gaps between vegetation foliage, ALS is generally unsuitable for deriving accurate and detailed information of individual trees, because its three-dimensional (3D) point clouds represent tree stems too sparsely. In contrast, point clouds from terrestrial laser scanning (TLS) feature very high point densities that allow for the reconstruction of the scanned object with millimetre accuracy. Therefore, TLS is currently the most accurate remote sensing method to derive detailed forest inventory information at the plot level [5]. Furthermore, in addition to the regular tree attributes measured in practical field inventories, more detailed tree attributes, such as the stem curve or taper curve (stem diameter as a function of height), which reveal the wood productivity and quality, can be derived from TLS with high degrees of accuracy [9]. Studies have explored the use of TLS at the plot level for assessing stem volume and biomass components [10-13] for individual tree reconstruction, including branches, twigs, and leaves [3,14,15], in order to improve the physiological understanding of tree growth [16]. Moreover, TLS has been used for determining the stem curve [17,18], which is not easily measurable using conventional tools. The drawbacks of this technology are the high costs of acquisition and data processing [19], the low portability of the system (with the exception of lightweight systems [20]), and the need for high expertise for processing the scanner data with specialized software. For providing accurate results, multiple scan positions are typically needed due to occlusions by stems, branches, twigs, and leaves [12]. While each scan requires only a few 
minutes, the total time needed to acquire appropriate TLS data for a whole forest plot is considerable. This consequently increases the labour cost of data acquisition and processing and in addition, the merged scans yield large point clouds, which can be difficult to handle. To reduce the time of data acquisition, mobile terrestrial systems mounted on backpacks are recently gaining popularity in forest inventory applications, because they enable fast data collection and have the main benefit of high mobility under various terrain conditions [20]. A mobile terrestrial system consists of a set of sensors that are carried by a human operator, for instance on a backpack, to acquire measurements of the environment while walking [21]. Mobile laser scanning systems for deriving canopy height profiles or the classical inventory parameters have recently been tested by [5,9,17,22-27]. However, providing complete and accurate data under the heterogeneous and complex forest conditions remains a major challenge for mobile laser scanning systems [5]. Also, their high costs and the huge amounts of data involved are an obstacle [21]. Furthermore, these mobile systems not only require the availability of GNSS satellite signals that can be poor in dense forests [5], but also accurate Real Time Kinematic positioning with base stations nearby [21]. Therefore, at this moment, mobile laser scanning in forest environments is still at a very early stage of development [5]. To reduce the costs of mobile systems, a backpack approach with multiple digital cameras was presented by [28], but issues similar to those for mobile laser scanning systems remain. Similarly, an omnidirectional system composed of eight single lens reflex (SLR) cameras was presented by [29]. However, due to the low image resolution, the measurement range of the system is limited to a radius of only $5 \mathrm{~m}$. With the goal of reducing the acquisition time, [30] used panoramic photography for deriving stem distribution. Furthermore, [31] investigated the potential of mobile phones cameras to derive tree stem diameters and tree heights for forest inventory.

Despite these few studies on mobile camera systems, most of the recent research on photogrammetrically deriving forest parameters has used a single, static camera, which is usually hand-held or attached to some form of tripod. For deriving forest parameters at the plot level, terrestrial photogrammetry features the advantages of low costs of the needed equipment, and a potentially simple and fast data acquisition [17]. Moreover, it has become even more attractive in recent years, because recent advancements in SfM photogrammetry and dense image matching have lowered the level of expertise required for deriving dense, accurate 3D point clouds. Finally, unlike TLS, cameras are highly mobile, allowing for overlapping photos to be taken from many different locations to achieve complete coverage.

Several studies have shown impressive photogrammetric reconstructions of individual trees (i.e., not an entire forest plot) under artificial conditions [32-34] and in natural forests [35-38]. The imaging environment in a natural forest poses a significant challenge due to the lighting conditions, tree density and occlusions by branches, and shrubs. To the best of our knowledge, only a small number of studies have evaluated terrestrial SfM photogrammetry in natural forests at plot scale (with diameters ranging from 10 to $40 \mathrm{~m}$ ) to acquire forest inventory parameters such as $\mathrm{DBH}$ and tree positions [17,39-43].

In this context, this study aims to improve the understanding of the applicability of terrestrial SfM photogrammetry for deriving, at the plot- and tree-level, the five measurements defined by [6] for TLS: the digital terrain model (DTM), tree count, tree position, $\mathrm{DBH}$, maximum measurable tree height, and stem curve. The main strength of our study is that the investigation was performed on four different forest plots, located in the vicinities of Vienna (Austria) and Zvolen (Slovakia), maintaining the same survey configuration for each plot. Therefore, the following research questions are addressed in this study: (1) Is the proposed imaging network (i.e., photographer's path, image overlap, intersection angles, resolution) a reliable method for reconstructing forest plots under different forest conditions? (2) What is the accuracy of the camera orientation and the derived DTM in comparison to TLS? (3) How many trees can be detected at breast height in comparison to field measurements and TLS? (4) What is the accuracy of the photogrammetric DBH in comparison to caliper measurements and TLS estimates? (5) What is the accuracy of the stem curve derived from photogrammetric point clouds with respect to 
TLS estimates, and what is the maximum stem height that can be reconstructed? Finally, we discuss the efficiency of terrestrial SfM photogrammetry in terms of the time needed to acquire and process the photogrammetric data.

\section{Study Site}

The investigation was conducted on four forest plots located in the vicinities of Vienna (Austria) and Zvolen (Slovakia) (Figure 1a, Table 1). The forest plots, two in each country, cover different forest and topographic conditions in terms of slope, forest density, growth stages and management activities, understory vegetation, and tree species.

(a)

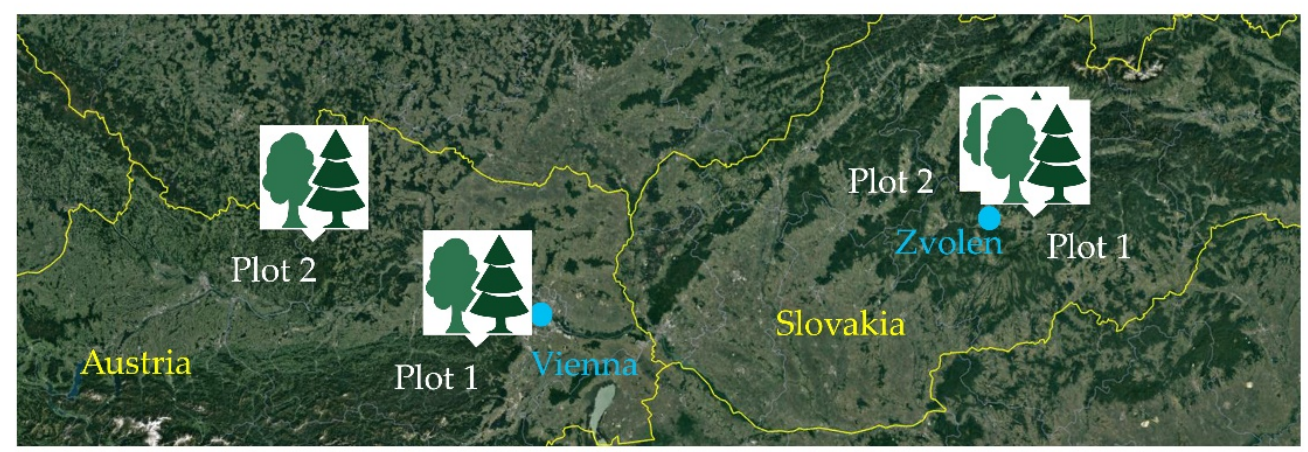

(b)

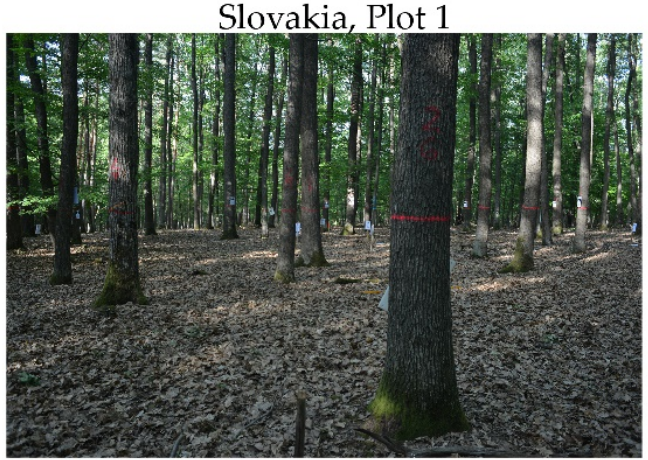

Austria, Plot 1

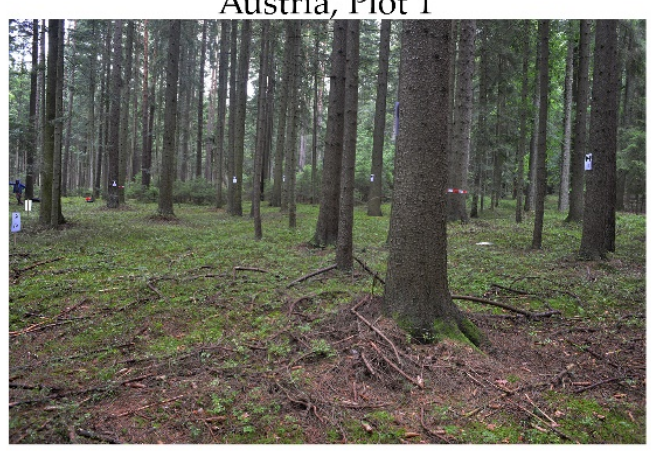

Slovakia, Plot 2

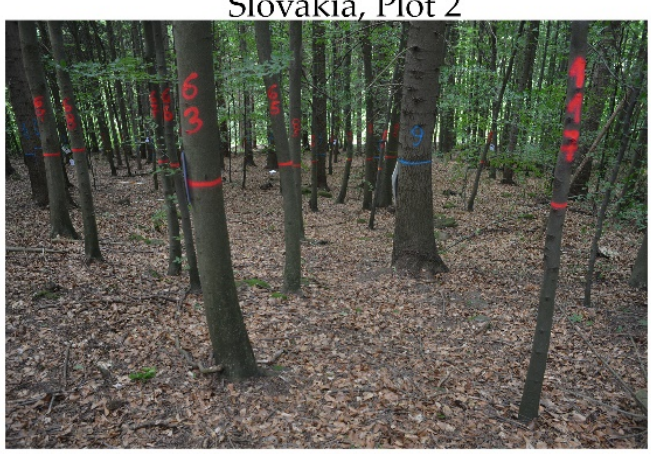

Austria, Plot 2

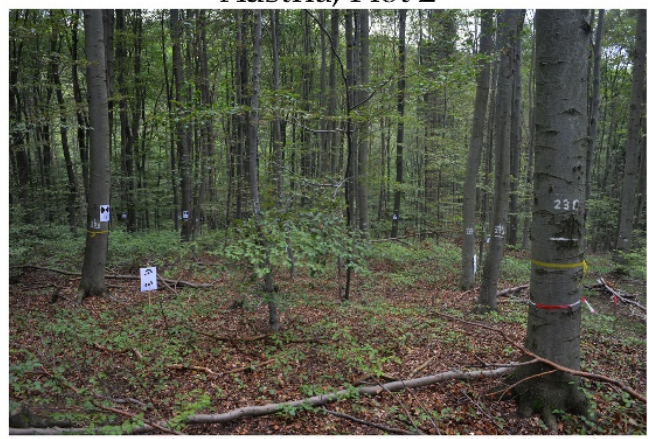

Figure 1. (a) Overview of the forest plot locations and (b) for each forest plot, a photo illustrating the forest at the time of the survey.

The two circular forest plots in Slovakia are part of the forest enterprise of Technical University in Zvolen. The plots have a diameter of $30 \mathrm{~m}$ (plot 1) and $40 \mathrm{~m}$ (plot 2). According to the field inventory, $\mathrm{DBH}$ values for plot 1 range from $9.7 \mathrm{~cm}$ to $41.9 \mathrm{~cm}$, with a mean value of $30.7 \mathrm{~cm}$ and a standard deviation $(\sigma)$ of $7.1 \mathrm{~cm}$, and for plot 2 from $6.4 \mathrm{~cm}$ to $58.9 \mathrm{~cm}$, with a mean value of $22.6 \mathrm{~cm}$ and a $\sigma$ of $13.1 \mathrm{~cm}$ (Table A1, Ref). The main tree species are Sessile oak (Quercus petraea Matt.) and European hornbeam (Carpinus betulus L.) on plot 1, and European silver fir (Abies alba Mill.) and European Beech (Fagus sylvatica L.) on plot 2. In Austria, plot 1 has a circular shape of $40 \mathrm{~m}$ diameter and plot 2 has 
a square shape of size 30 by $30 \mathrm{~m}$. The dominating tree species on both plots are Norway spruce (Picea abies L.), European beech (Fagus sylvatica L.), Sessile oak (Quercus petraea Matt.), and European hornbeam (Carpinus betulus L.) (Figure 1, Table 1). The DBHs range from 9.3 to $63.9 \mathrm{~cm}$ (with a mean value of $29.8 \mathrm{~cm}$ and a $\sigma$ of $14.3 \mathrm{~cm}$ ) on plot 1, and from 5.7 to $40.8 \mathrm{~cm}$ (with a mean value of $24.2 \mathrm{~cm}$ and a $\sigma$ of $11.4 \mathrm{~cm}$ ) on plot 2 (Table A1, Ref).

According to the spatial stem distribution and density and the DBH distribution [5], plot 1 in Slovakia can be seen as "easy", plot 1 in Austria as "medium", and plot 2 in both Slovakia and Austria as "difficult". Figure $1 \mathrm{~b}$ gives an impression of the complexity of each forest plot at the time of the survey. All the plots were surveyed under leaf-on conditions.

Table 1. Acquisition dates and characteristics of each plot.

\begin{tabular}{|c|c|c|c|c|c|c|c|}
\hline $\begin{array}{l}\text { Study } \\
\text { Plot }\end{array}$ & $\begin{array}{l}\text { Lat.N/ } \\
\text { Long.E }\end{array}$ & $\begin{array}{l}\text { Acqu. } \\
\text { Dates }\end{array}$ & $\begin{array}{l}\text { Plot Size } \\
\text { [m], Shape }\end{array}$ & $\begin{array}{c}\text { Stem } \\
\text { Density } \\
\text { [stems/ha] }\end{array}$ & $\begin{array}{c}\text { Tree } \\
\text { Species }\end{array}$ & $\begin{array}{l}\text { Complexity } \\
\text { Categories }\end{array}$ & $\begin{array}{l}\text { Average } \\
\text { Slope }\left[{ }^{\circ}\right]\end{array}$ \\
\hline $\begin{array}{l}\text { Slovakia, } \\
\text { Plot } 1\end{array}$ & $\begin{array}{c}48^{\circ} 36^{\prime} \mathrm{N} \\
19^{\circ} 5^{\prime} \mathrm{E}\end{array}$ & $\begin{array}{l}22 \text { June } \\
2017\end{array}$ & 30 , circular & 651 & $\begin{array}{l}\text { Quercus } \\
\text { petraea }\end{array}$ & easy & 5 \\
\hline $\begin{array}{l}\text { Slovakia, } \\
\text { Plot } 2\end{array}$ & $\begin{array}{c}48^{\circ} 38^{\prime} \mathrm{N} \\
19^{\circ} 3^{\prime} \mathrm{E}\end{array}$ & $\begin{array}{l}23 \text { June } \\
2017\end{array}$ & 40, circular & 875 & $\begin{array}{c}\text { Abies alba } \\
\text { Fagus } \\
\text { sylvatica }\end{array}$ & difficult & 17 \\
\hline $\begin{array}{l}\text { Austria, } \\
\text { Plot } 1\end{array}$ & $\begin{array}{l}48^{\circ} 31^{\prime} \mathrm{N} \\
15^{\circ} 11^{\prime} \mathrm{E}\end{array}$ & $\begin{array}{c}11 \\
\text { September } \\
2017\end{array}$ & 40, circular & 390 & $\begin{array}{c}\text { Fagus } \\
\text { sylvatica }\end{array}$ & medium & 7 \\
\hline $\begin{array}{l}\text { Austria, } \\
\text { Plot } 2\end{array}$ & $\begin{array}{l}48^{\circ} 7^{\prime} \mathrm{N} \\
16^{\circ} 2^{\prime} \mathrm{E}\end{array}$ & $\begin{array}{c}12 \\
\text { September } \\
2017\end{array}$ & 30, square & 533 & Picea abies & difficult & 15 \\
\hline
\end{tabular}

\section{Methods}

For each forest plot, the following surveying methodology was adopted to acquire the dataset: (i) DBH caliper measurements; (ii) topographic survey with total station to measure the tree positions and the photogrammetric and TLS targets; (iii) TLS acquisition of the forest plot at multiple scan positions; (iv) terrestrial photogrammetric survey with overlapping images. All measurements were acquired in local coordinates defined by the total station, which was located approximately at the plot centre. The caliper measurements of the DBHs and the tree positions from the total station survey were used as reference (named Ref) for validating the respective results from photogrammetry and TLS. Stem curves derived from TLS were used as reference for those from photogrammetry. According to [6], the stem curve of an individual tree consists of "stem diameters starting at the height of $0.65 \mathrm{~m}$ above the ground, followed by diameters at the DBH height and at every meter above the DBH height, i.e., $0.65 \mathrm{~m}, 1.3 \mathrm{~m}, 2 \mathrm{~m}, 3 \mathrm{~m}$, and so on, until reaching the maximum measurable heights from the point cloud data". Exceeding this definition, we derived the stem diameters every $50 \mathrm{~cm}$ above the DBH height. Detailed descriptions of the data acquisition and the TLS and photogrammetric workflows to produce the dense point clouds are given in the next sections.

\subsection{Field Inventory: Total Station, Caliper}

Tree positions at breast height were measured with a Topcon GPT 3002 total station. The distance was measured to the middle point of a side of the tree, while the angle was subsequently offset from the side to the centre. Photogrammetric and TLS targets were measured using prism-less distance measurement. DBHs were measured using a caliper in two perpendicular directions (one in the direction of the greatest terrain slope, and the other parallel to contour lines), which is a standard procedure in field inventory. Not all the trees with DBHs smaller than $8 \mathrm{~cm}$ were measured. 


\subsection{TLS Survey}

The scanner was placed at multiple positions, approximately along the border of each plot. To also capture otherwise occluded trees, the surveys were completed by scans inside the plot areas. This multi-scan approach follows a common strategy for TLS forest inventory, where the number of scan positions is a trade-off between the accuracy and completeness of the point cloud and the acquisition time, which must be chosen according to the forest plot complexity. In Slovakia, a Zoller \& Fröhlich 5010C scanner was used, and for the plots in Austria, a Riegl VZ-2000. Targets were employed for the registration of the scans. For the Austrian plots, retro-reflective targets (diameter $5 \mathrm{~cm}$ ) were distributed around the plot, and they were automatically scanned by TLS at highest resolution. On the Slovakian plots, only 5 automatically recognizable targets were available, and therefore photogrammetric targets were used for the registration of the scans. The distribution of the scans and the registration targets can be seen in Figure A2. The horizontal and vertical angular resolutions were set to $0.06^{\circ}$, resulting in a lateral point spacing of about $3 \mathrm{~cm}$ at $30 \mathrm{~m}$ distance from the scanner.

\subsection{Terrestrial Photogrammetric Survey}

Overlapping digital terrestrial images were taken in landscape format with a Nikon D800 digital SLR camera and a focal length of $28 \mathrm{~mm}$. The aperture sizes of $\mathrm{f} 7.1$ and $\mathrm{f} 8 \mathrm{in}$ Slovakia and Austria, respectively, were chosen according to the present lighting conditions, and the focus was fixed to infinity. Given the focal length and pixel size, the image resolution at a distance of the average plot diameter results as about $7 \mathrm{~mm}$. Targets were used in the field to determine the scale of the photogrammetric survey. Each target consisted of a laminated A4 paper sheet with a black and white circular pattern printed onto it (Figure A1). The targets were nailed onto the tree stems, distributed homogenously within the plot and along its border (Figure A2). Only 4 or 5 targets were used as ground control points (GCPs), while the majority (13 or 14) were considered as check points (CPs) for accuracy evaluation (Table 2).

We tested several methods of traversing a forest plot and capturing a stable and complete network of overlapping images along the way, and we outline the method found to produce the best image orientation with smallest RMSEs at the CPs. This consists of a base sequence of overlapping photos, which is then augmented for difficult plots, resulting in a combination of the photographic paths suggested by $[17,39,42]$. The trajectory adopted to capture the overlapping images starts with an image sequence in stop and go mode [18] taken along the perimeter of the forest plot, pointing the camera at the plot centre. Having completed this perimeter, the photographer moves inside the plot to acquire a second sequence along a smaller circle, pointing the camera outwards. This method was used in plot 1 in Slovakia (Figure A1). For the more complex and larger plots, the photographer additionally takes images along two perpendicular paths across the plot. This extended photographic path was adopted for both forest plots in Austria and for the second plot in Slovakia (Figure A1). For the latter, additional photos were acquired also along two parallels strips to avoid occlusions by stems, branches, twigs, and leaves due to the dense tree distribution in the north-western part of the plot. The sequence of images was acquired while maintaining a mean baseline between adjacent camera positions of about 1 $\mathrm{m}$, resulting in a number of photos ranging between 338 and 775 (Table 2). The camera was attached to a lightweight tripod to ensure good image quality of the images. The camera axis on the tripod was set roughly horizontal, and multiple convergent images were included in the imaging geometry.

Table 2. Overview of the conducted photogrammetric and TLS surveys, and the resulting point clouds.

\begin{tabular}{cccccccccc}
\hline \multirow{2}{*}{ Study Plot } & \multicolumn{9}{c}{ SfM } \\
\cline { 2 - 11 } & $\begin{array}{c}\text { No. } \\
\text { Camera }\end{array}$ & $\begin{array}{c}\text { No. } \\
\text { GCPs }\end{array}$ & $\begin{array}{c}\text { No. } \\
\text { CPs }\end{array}$ & $\begin{array}{c}\text { Pts Dense } \\
\text { Cloud }\end{array}$ & $\begin{array}{c}\text { Pts after } \\
\text { Filtering }\end{array}$ & $\begin{array}{c}\text { No. } \\
\text { Scans }\end{array}$ & $\begin{array}{c}\text { No. } \\
\text { Targets }\end{array}$ & $\begin{array}{c}\text { Pts Dense } \\
\text { Cloud }\end{array}$ & $\begin{array}{c}\text { Pts after } \\
\text { Filtering }\end{array}$ \\
\hline Slovakia, Plot 1 & 338 & 4 & 14 & $47,800,000$ & $38,700,000$ & 9 & 25 & $379,466,950$ & $18,012,654$ \\
Slovakia, Plot 2 & 775 & 5 & 13 & $87,900,000$ & $73,500,000$ & 12 & 23 & $152,264,516$ & $11,322,459$ \\
Austria, Plot 1 & 531 & 5 & 13 & $27,300,000$ & $20,900,000$ & 19 & 21 & $194,578,612$ & $56,584,040$ \\
Austria, Plot 2 & 632 & 5 & 13 & $42,700,000$ & $39,600,000$ & 15 & 30 & $20,180,795$ & $11,803,353$ \\
\hline
\end{tabular}




\subsection{TLS and Photogrammetric Data Processing}

\subsubsection{TLS Point Cloud Generation}

Registration of the TLS scans and post-processing steps were done with standard software provided by each scanner manufacturers. Both software packages allow for automatically detecting the manufacturer-specific targets. However, since for the Zoller \& Fröhlich scans, only 5 of them had been captured, the photogrammetric targets were also used for TLS registration, which hence needed to be picked semi-automatically in the intensity images of the scan data. With many targets detected in multiple scans and some of them having been observed by the total station, the adjusted scanner orientations referred to each plot's local coordinate system, with accuracies in the range of a few millimetres. After registration, the merged point clouds were freed from clutter like edge artefacts and unresolved objects (branches smaller than the footprint size) and the oblique rays near ground. This filtering was done by thresholding the intensity for both scanners. Later on, a regular subsampling of $1 \mathrm{~cm}$ was performed to reduce the point cloud size. See Table 2 for the number of TLS points after post-processing.

\subsubsection{SfM Point Cloud Generation}

The commercial software PhotoScan Pro (v 1.2.4) was adopted to derive dense point clouds from the overlapping images. An overview of its workflow can be found in [44]. It consists of four main steps: (1) initial camera orientation, (2) GCPs and CPs identification in the images, (3) final camera orientation (bundle block adjustment) including scale definition/geo-referencing, and (4) dense point cloud computation based on dense image matching. In this paper, SfM refers to this workflow, for which Figure 2 outlines a schematic illustration, together with the selected parameters. Within the final bundle block adjustment, a camera self-calibration was performed. To reduce the computation time, dense image matching was done at half the image resolution. Noise in the dense point cloud was filtered using the S.O.R. (Statistical Outlier Removal) implemented in the open source software Cloud Compare by setting 50 nearest neighbours and 1 standard deviation [45]. See Table 2 for the number of SfM points after filtering.

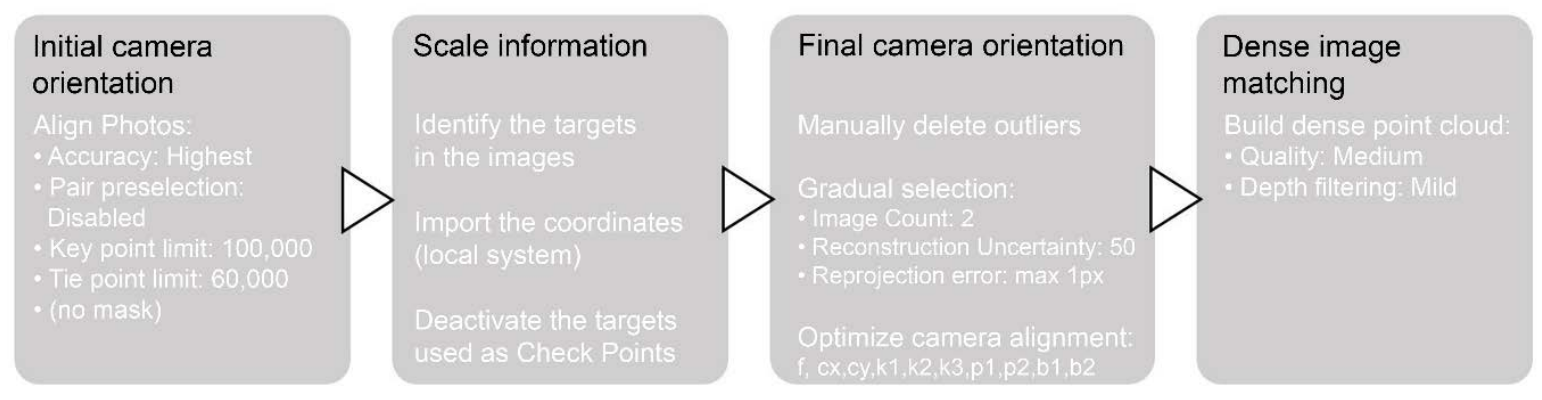

Figure 2. Workflow and parameters used for point cloud generation with Agisoft PhotoScan.

\subsection{DTM and Forest Variable Estimation: Tree Detection, DBH and Stem Curve}

For generating DTMs, the SfM and TLS points were first classified into ground and off-ground. DTMs with $20 \mathrm{~cm}$ resolution were generated based on a hierarchical approach [46,47]. Its main assumption is that the lower a point is located, the more probably it belongs to the terrain. Therefore, the terrain surface is approximated at increasing resolutions, where points below the current model are given larger weights than those above. In the end, all points not exceeding a certain absolute height deviation are weighted equally to derive the final DTM [48]. The entire workflow is implemented as a batch script using the software Orientation and Processing of Airborne Laser Scanning data (OPALS) developed at TU Wien [49]. 
For each forest plot, the DTMs generated from SfM and TLS point clouds (see the hillshade DTMs, Figure A2) were used to calculate the height above ground. Terrain points were excluded from the derivation of forest variables and all non-terrain points were additionally filtered using a robust segmentation approach proposed in [50]. Subsequently, we automatically derived for both the SfM and TLS point clouds the locations and the numbers of trees, the DBHs, and the stem curves using a software developed at TU Wien (Forest Analysis and Inventory Tool, FAIT). Within FAIT, each point cloud was subsampled with a voxel size of $2 \mathrm{~cm}$ in order to reduce the computation time. FAIT identifies stem points as those corresponding to large linear segments. It clusters the detected stem points into individual stems using the mean-shift algorithm [51]. Finally, it models the stems by fitting a series of cylinders, based on a 2D-3D robust cylinder fitting strategy [18,47]. To smooth the connection parts of successive cylinders, a truncated cone is generated, and then, their diameters and centre locations are extracted at the wanted heights above ground for each stem [18]. This workflow was applied to the SfM and TLS point clouds with the same set of parameters, and this is illustrated in Figure 3.

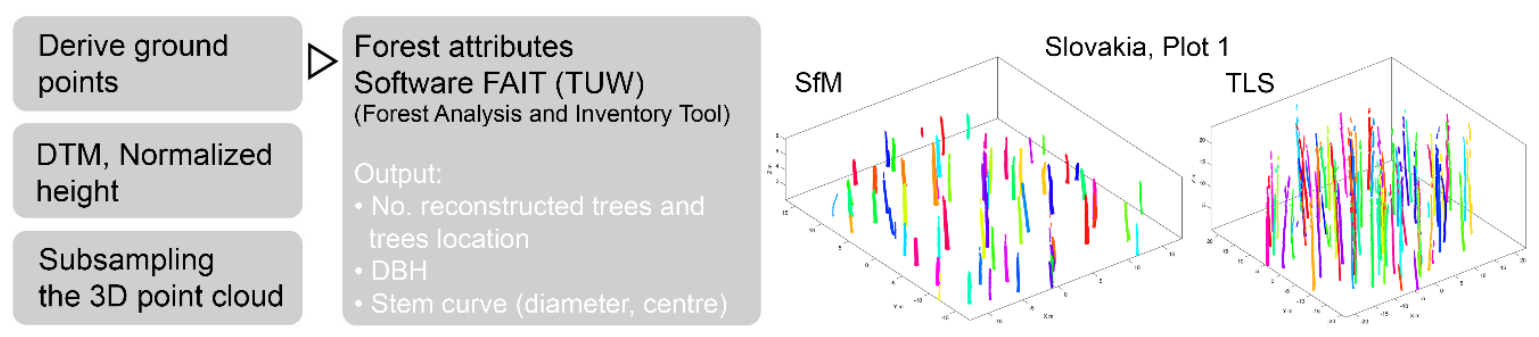

Figure 3. FAIT workflow to derive DBHs and the stem curves from a point cloud. On the right, an example of the stem modelling for plot 1 in Slovakia.

\subsection{Data Analyses}

For each forest plot, the accuracy of camera orientations was quantified by the root mean square error (RMSE) of forward intersected object coordinates with respect to $\mathrm{CP}$ coordinates measured with the total station. Additionally, the accuracy of the SfM ground height was estimated by comparing the SfM DTM with the TLS DTM. The statistical values of mean, RMSE and median of the height differences between these DTMs were calculated for accuracy evaluation.

For each plot, we restricted all further analyses to the area within the plot boundary, defined by the camera path around the plot. Correspondences between trees from different surveys (i.e., SfM vs. Ref, TLS vs. Ref and SfM vs. TLS) were determined as those having mutually nearest neighbouring positions at breast height in the $\mathrm{XY}$ plane.

The completeness of stem detection from SfM and TLS data was assessed as the respective number of corresponding trees.

For the accuracy analyses, only corresponding trees were considered. The accuracies of the DBH estimates were assessed by calculating the bias, RMSE $[37,39]$ and the median of errors. The accuracy of SfM stem curves was assessed by calculating the bias of the stem diameters and stem centres with respect to the corresponding TLS estimates.

\section{Results}

\subsection{Accuracy Assessment of the Image Orientation and SfM DTMs}

Image orientation and dense image matching were successful on all forest plots. Thanks to the high quality of the images and the strong imaging geometry in terms of image overlap and intersection angles, all the acquired images were properly oriented. For all the plots, every spot on the ground is observed by more than nine images. The RMSE of the GCPs is in the range of a millimetre both in the horizontal and vertical directions (Table 3). However, these observations were included in 
the bundle block adjustments, which minimize their errors. An independent accuracy assessment of image orientation is provided by the RMSEs of the CPs, which are of the same order as for the GCPs in planimetry, and about $0.4 \mathrm{~cm}$ in the vertical direction (Table 3). For all forest plots, dense matching ensured an almost complete reconstruction of the terrain features. Higher elevation differences are all located around the trees stems. Larger void areas are mainly located at the plot centres and at their borders, which were reliably interpolated by the DTMs; however (Figure 4). For these areas, the height differences between the SfM and TLS DTMs show larger errors, especially on the Austrian plots, with a maximum absolute difference of $91 \mathrm{~cm}$ (Table 3). These plots are characterized by rough terrain with ground vegetation, leaves and branches, whereas the ground of the plots in Slovakia is relatively clear of vegetation. In general, for all the plots the spatial distribution of the height differences of the SfM DTM with respect to TLS does not show systematic errors. The mean deviation of the SfM DTM of each plot ranges from $-0.2 \mathrm{~cm}$ to $1.8 \mathrm{~cm}$, with the steepest plot having the smallest absolute value (Slovakia plot 2).

Table 3. RMSEs of GCPs and CPs for each plot, and height differences between SfM and TLS DTMs.

\begin{tabular}{|c|c|c|c|c|c|c|c|c|c|c|}
\hline \multirow{3}{*}{ Study Plot } & \multicolumn{3}{|c|}{ GCPs } & \multicolumn{3}{|c|}{ CPs } & \multirow{2}{*}{\multicolumn{4}{|c|}{$\begin{array}{l}\text { Height Differences } \\
\text { SfM-TLS DTM [cm] }\end{array}$}} \\
\hline & \multirow{2}{*}{$\begin{array}{l}\text { Avg } \\
\text { no. Rays }\end{array}$} & \multicolumn{2}{|c|}{ RMSE [cm] } & \multirow{2}{*}{$\begin{array}{c}\text { Avg } \\
\text { no. Rays }\end{array}$} & \multicolumn{2}{|c|}{ RMSE [cm] } & & & & \\
\hline & & xy & $\mathbf{z}$ & & $\mathbf{x z}$ & $\mathbf{z}$ & Min/Max & Mean & RMSE & Median \\
\hline Slovakia, Plot 1 & 70 & 0.39 & 0.00 & 71 & 0.39 & 0.33 & $-12.0 / 37.9$ & 0.61 & 1.93 & 0.61 \\
\hline Slovakia, Plot 2 & 78 & 0.68 & 0.08 & 105 & 0.76 & 0.43 & $-32.5 / 46.6$ & -0.24 & 2.03 & -0.30 \\
\hline Austria, Plot 1 & 110 & 0.29 & 0.19 & 106 & 0.31 & 0.34 & $-36.0 / 46.8$ & 1.77 & 4.81 & 1.33 \\
\hline
\end{tabular}

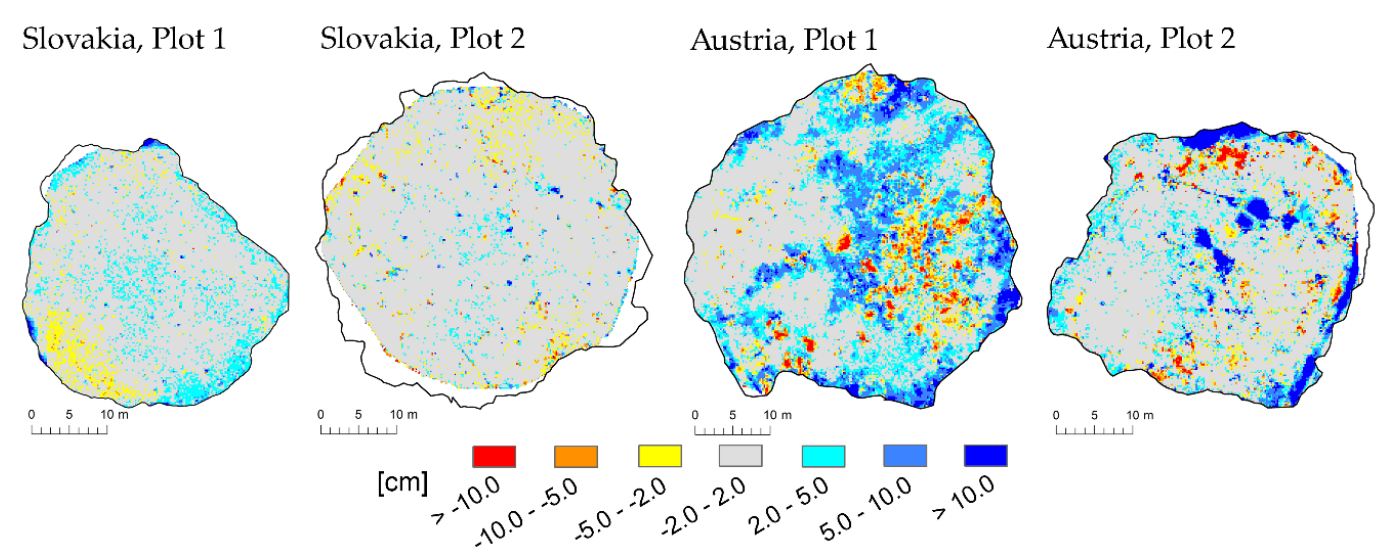

Figure 4. For each plot, the height differences between SfM and TLS DTMs. The black lines indicate the plot boundaries defined by the camera path around the plot.

\subsection{Forest Variable Estimation: Stem Detection, DBH and Stem Curve}

\subsubsection{Stem Detection}

Figure 5 shows the trees within each plot boundary that were measured (Ref) and automatically estimated from the SfM and TLS point clouds. This overlay of reference stem positions together with those derived from SfM and TLS point clouds makes it evident that all the three methods missed some trees (Figure 5, Table 4). A large number of trees omitted both by SfM and TLS (red circles in Figure 5) is notable in Slovakia plot 2, although they have reference DBHs smaller than $20 \mathrm{~cm}$. Furthermore, it is worth noting that many of the trees identified both by SfM and TLS close to the plot borders were not measured, likely due to slightly different plot boundary definitions used for the field inventories. Moreover, some trees with DBHs smaller than $8 \mathrm{~cm}$ were not measured. This justifies the larger number of trees detected by TLS (90) in comparison to the reference (66) in plot 1 in Austria (Table 4). 
The completeness of stem detection from SfM and TLS data was assessed with respect to the reference measurements (see Section 3.6). For each plot, $65 \%$ to $98 \%$ of all reference stems were detected in the SfM data, while these values range from $79 \%$ to $100 \%$ for TLS data. By both data types, the lowest percentage of reference stems was detected for the forest plot classified as difficult (Slovakia plot 2).
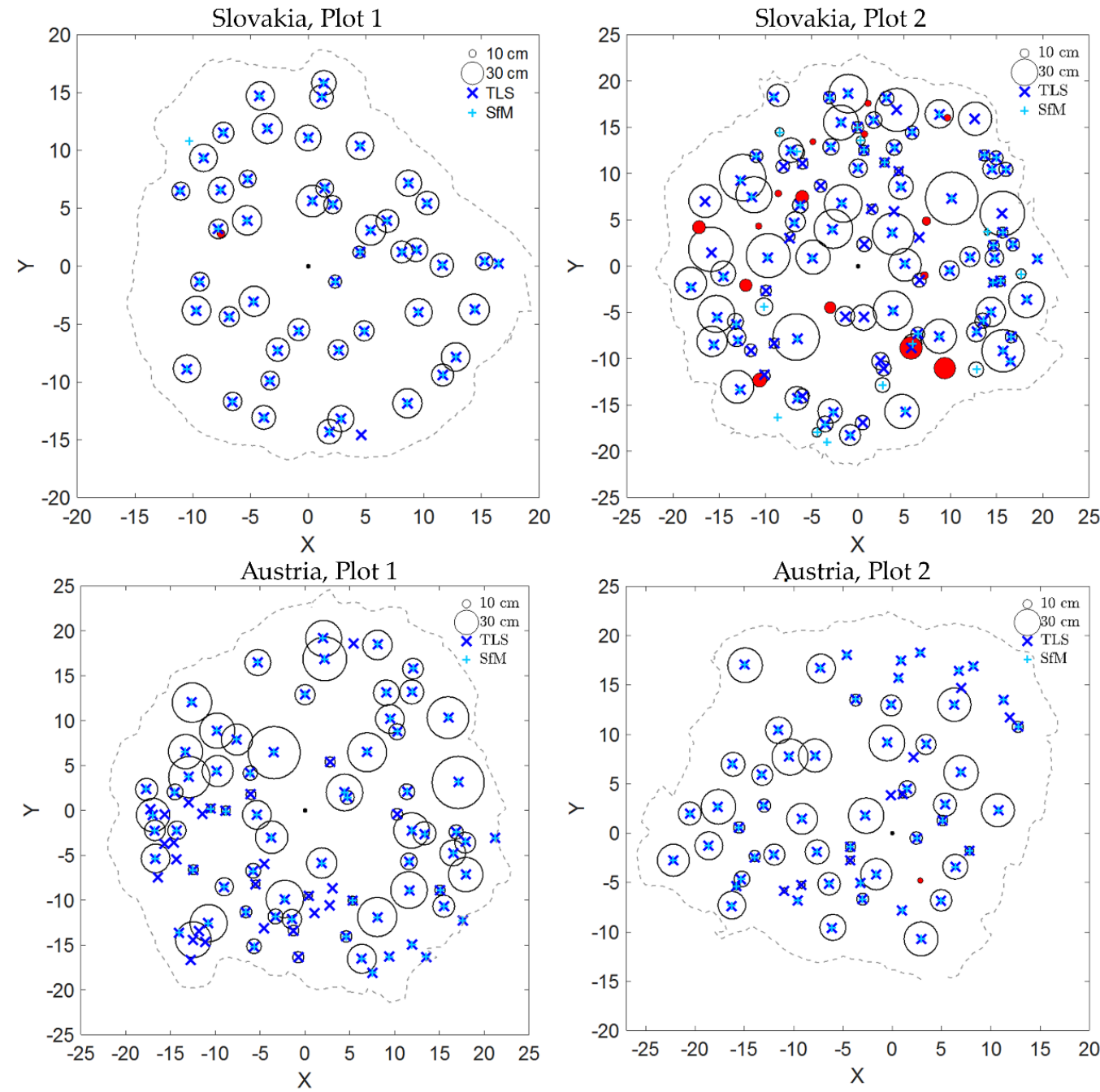

Figure 5. Tree locations and corresponding DBHs for each forest plot. Reference DBHs are shown as black circles of respective diameters, centred at their reference positions. Trees identified by TLS are shown in blue, and those detected by SfM in turquoise. The circles of reference DBHs identified neither by TLS, nor by SfM are filled with red. The dashed lines indicate the plot boundaries.

Table 4. Completeness of tree stem detection.

\begin{tabular}{ccccccccc}
\hline \multirow{2}{*}{ Study Plot } & \multicolumn{3}{c}{$\begin{array}{c}\text { No. of Detected } \\
\text { Trees }\end{array}$} & \multicolumn{2}{c}{$\begin{array}{c}\text { No. of Corresponding Trees } \\
\text { [no. (\%)] }\end{array}$} & \multicolumn{2}{c}{$\begin{array}{c}\text { Average DBH (Ref.) } \\
\text { of Missing Trees [cm] }\end{array}$} \\
\cline { 2 - 9 } & SfM & TLS & Ref & SfM vs. Ref & TLS vs. Ref & SfM vs. TLS & SfM & TLS \\
\hline Slovakia, Plot 1 & 47 & 47 & 46 & $45(98)$ & $45(98)$ & $46(98)$ & 9.7 & 9.7 \\
Slovakia, Plot 2 & 76 & 90 & 110 & $72(65)$ & $87(79)$ & $67(74)$ & 17.7 & 12.2 \\
Austria, Plot 1 & 61 & 90 & 66 & $55(83)$ & $66(100)$ & $61(68)$ & 12.6 & - \\
Austria, Plot 2 & 52 & 60 & 47 & $43(91)$ & $46(98)$ & $52(87)$ & 7.5 & 5.7 \\
\hline
\end{tabular}


The difficulty of reconstructing the stem at breast height of young or bended trees from SfM point clouds becomes obvious in the inset of Figure 6 (Austria plot 2). Despite the limited capacity of SfM to reconstruct young trees with small DBHs, its photos and coloured point cloud offer the possibility to visually detect trees that are reconstructed only partially and consequently missed by the automatic stem detection. In this forest plot, $91 \%$ of reference stems were detected from the SfM point cloud, and $98 \%$ from the one of TLS. $87 \%$ of the trees detected by TLS were also detected by SfM. It is worth noting that the subsampling of all point clouds with a voxel size of $2 \mathrm{~cm}$ for tree detection renders the estimation of stems with diameters of less than $6 \mathrm{~cm}$ unreliable or even impossible.

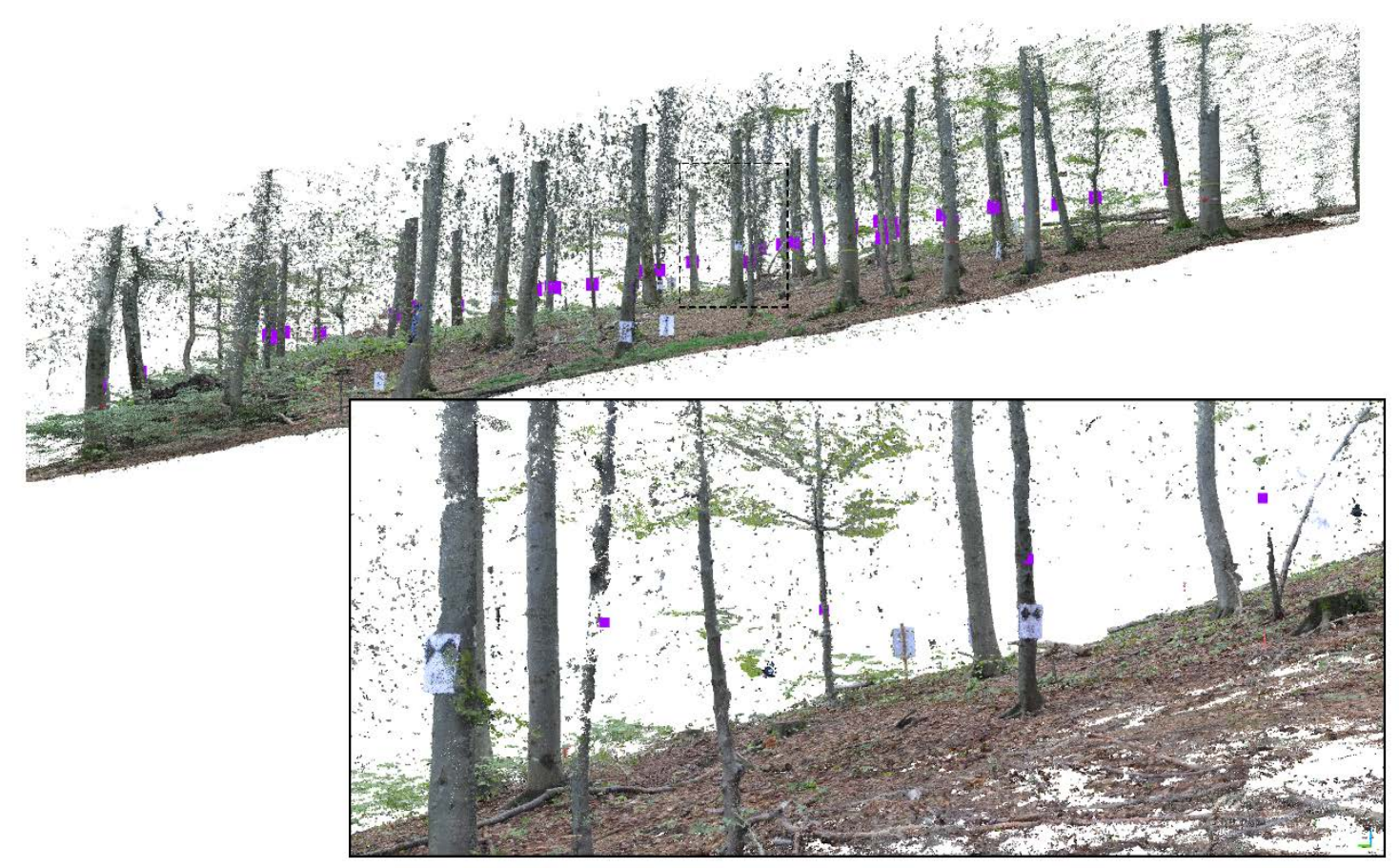

Figure 6. Coloured SfM point cloud of plot 2 in Austria, overlaid with the location of the trees measured by the total station (the magenta square dots). The dashed line indicates the location of the enlarged point cloud at the bottom.

\subsubsection{DBH}

A simple linear regression analysis was used to compare the SfM and TLS DBH estimates with the reference DHB, as well as the SfM with respect to the TLS (Figure A3). Besides high correlation values, the linear regression highlights the presence of outliers in both SfM and TLS DBH estimates. These outliers are caused by wrong tree correspondences. The selection of corresponding trees between two methods was performed automatically (see Section 3.6) and it might be wrong when trees in one of the two datasets are missing.

The presence of gross errors is also noticeable when plotting the differences between the SfM and TLS DBH estimates and the measured DBH in relation to the DBH values (Figure 7). In addition, the figure suggests that neither for SfM, nor for TLS DBH estimates, there is a clear dependency of the $\mathrm{DBH}$ error on the reference $\mathrm{DBH}$ value, as expected from the mean being not statistically different. However, both methods generally underestimate the DBHs of adult trees with respect to the reference measurements. With the intention of assessing the accuracy of the DBH estimates, the bias, RMSE and median are reported in Table 5. The bias of the SfM DBH estimates ranges between $-2.07 \mathrm{~cm}$ and $-0.71 \mathrm{~cm}$, with a maximum RMSE of $5.07 \mathrm{~cm}$ and an absolute median of $1.42 \mathrm{~cm}$ (Table 5). The bias of the TLS DBH estimates ranges between $-1.19 \mathrm{~cm}$ and $-0.38 \mathrm{~cm}$, with a maximum RMSE of $3.75 \mathrm{~cm}$ and absolute median of $0.63 \mathrm{~cm}$. The SfM DBH estimates reveal higher accuracy with respect to TLS with a maximum bias of $-1.14 \mathrm{~cm}$, RMSE of $4.31 \mathrm{~cm}$ and absolute median of $0.65 \mathrm{~cm}$. 
The statistics show that the most accurate DBH estimation is achieved for the easy plot by both methods likely due to the absence of outliers (Figure A3). Overall, in four forest plots, the mean of the error of the SfM DBHs with the reference is $-1.13 \mathrm{~cm}$ and $-0.45 \mathrm{~cm}$ with respect to the TLS (Figure A4a,b).

The Mann-Whitney U (Wilcoxon rank) test was performed to test the significance of differences between the mean SfM DBH estimates with respect to the mean reference DBH (caliper) and TLS DBH, and similarly for the mean TLS DBH estimates with respect to the reference. This nonparametric test was considered due to the low number of DBH observations for each plot, and to overcome the non-normal distribution of the analysed variables. The results show that the differences between both SfM and TLS DBH mean estimates with the reference mean that DBH are not statistically significant, with a $\mathrm{p}$ value much greater than 0.05 (with $\mathrm{p}$ ranging from 0.41 to 0.82 ). Similar results were obtained by comparing mean SfM with mean TLS DBH estimates (with p ranging from 0.66 to 0.99 ). Therefore, the test suggests that the differences of DBHs estimated or measured by the three methods are insignificant. This is also confirmed by comparing the statistics such as min, max, mean and $\sigma$ of the DBH values for each method (Table A1).
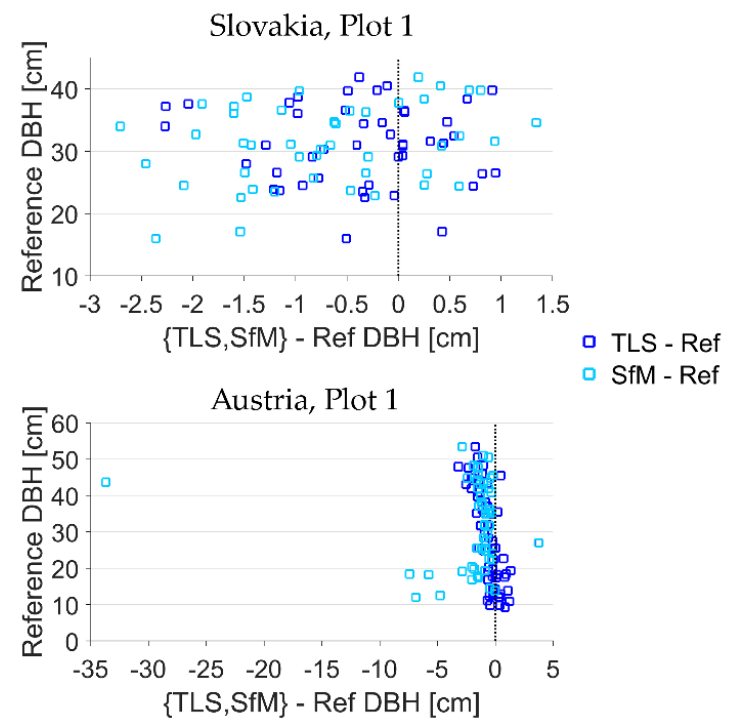

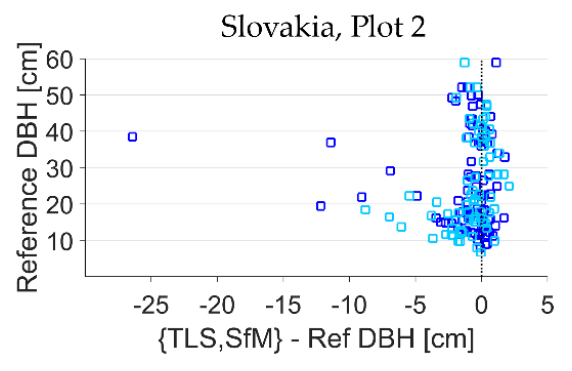

Austria, Plot 2

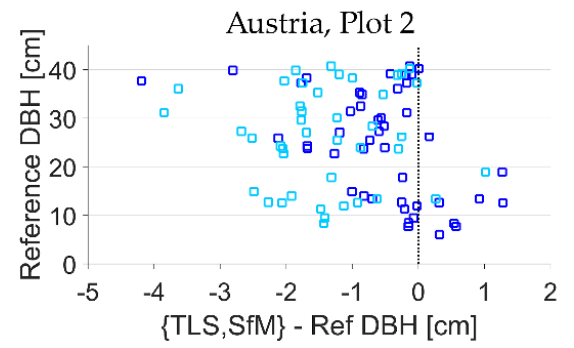

Figure 7. For each plot, and for both SfM and TLS, the DBH error in relation to the reference DBH.

Table 5. The accuracy of the DBH estimates from SfM and TLS point clouds.

\begin{tabular}{|c|c|c|c|c|c|c|c|c|c|c|c|c|}
\hline \multicolumn{13}{|c|}{ DBH Error [cm] } \\
\hline \multirow[b]{2}{*}{ Study Plot } & \multicolumn{4}{|c|}{ SfM vs. Ref } & \multicolumn{4}{|c|}{ TLS vs. Ref } & \multicolumn{4}{|c|}{ SfM vs. TLS } \\
\hline & $\begin{array}{c}\text { No. } \\
\text { Trees }\end{array}$ & Bias & RMSE & Median & $\begin{array}{c}\text { No. } \\
\text { Trees }\end{array}$ & Bias & RMSE & Median & $\begin{array}{c}\text { No. } \\
\text { Trees }\end{array}$ & Bias & RMSE & Median \\
\hline Slovakia, Plot 1 & 45 & -0.71 & 1.21 & -0.76 & 45 & -0.38 & 0.87 & -0.33 & 46 & -0.33 & 0.85 & -0.28 \\
\hline Slovakia, Plot 2 & 72 & -0.88 & 2.07 & -0.50 & 87 & -1.19 & 3.75 & -0.32 & 67 & 0.33 & 4.31 & 0.11 \\
\hline Austria, Plot 1 & 55 & -2.07 & 5.07 & -1.15 & 66 & -0.64 & 1.38 & -0.63 & 61 & -1.14 & 3.14 & -0.38 \\
\hline Austria, Plot 2 & 43 & -0.79 & 4.02 & -1.42 & 46 & -0.57 & 1.13 & -0.47 & 52 & -0.73 & 1.36 & -0.65 \\
\hline
\end{tabular}

\subsubsection{Stem Curve}

The mean differences between the SfM and TLS stem diameters and the mean offsets of the stem centres at different heights are reported in Table 6. At breast height, the mean stem diameter error agrees with the accuracy of the DBH derived by cylinder fitting (Table 5). From the ground to the height of $2.8 \mathrm{~m}$, the SfM stem curve errors range between -2.45 and $0.58 \mathrm{~cm}$, on average, and with a median between -1.83 and $0.39 \mathrm{~cm}$ (Table A2). A mean stem curve error up to $5 \mathrm{~cm}$ is achieved for heights above ground higher than $2.8 \mathrm{~m}$. At this height, the mean offset of the stem centre is about 
$3 \mathrm{~cm}$, while it decreases below $2 \mathrm{~cm}$ for lower heights. Furthermore, the number of reconstructed stem diameters significantly decreased with height (Figure 8). The maximum height reconstructed by the images taken in landscape format ranges between 4.3 and $11.3 \mathrm{~m}$. However, the overall accuracy of the stem curve at elevations higher than $2.8 \mathrm{~m}$ is beyond the required level of accuracy. For all the forest plots, results show that the stem diameters can be reconstructed up to $2.8 \mathrm{~m}$ above ground with centimetre accuracy, and similar accuracies are achieved regarding the position of the stem centre (Figure A3c,d).

Table 6. Mean SfM stem curve error.

\begin{tabular}{|c|c|c|c|c|c|c|c|c|c|c|c|c|c|}
\hline \multicolumn{14}{|c|}{ Stem Curve Error [cm], SfM vs. TLS } \\
\hline \multirow[t]{2}{*}{ Study Plot } & \multirow{2}{*}{$\begin{array}{c}\text { No. } \\
\text { Trees }\end{array}$} & \multicolumn{6}{|c|}{ Height above Ground [m] } & \multicolumn{6}{|c|}{ Height above Ground [m] } \\
\hline & & 0.65 & 1.30 & 1.80 & 2.30 & 2.80 & $>2.80$ & 0.65 & 1.30 & 1.80 & 2.30 & 2.80 & $>2.80$ \\
\hline Slovakia, Plot 1 & 45 & -0.33 & -0.58 & -1.13 & -1.71 & -2.45 & -5.37 & 1.27 & 1.07 & 1.15 & 1.27 & 1.54 & 2.86 \\
\hline Austria, Plot 2 & 43 & -1.79 & -2.01 & -2.41 & -2.69 & -2.32 & -3.83 & 1.77 & 1.34 & 1.28 & 1.39 & 1.42 & 2.72 \\
\hline
\end{tabular}
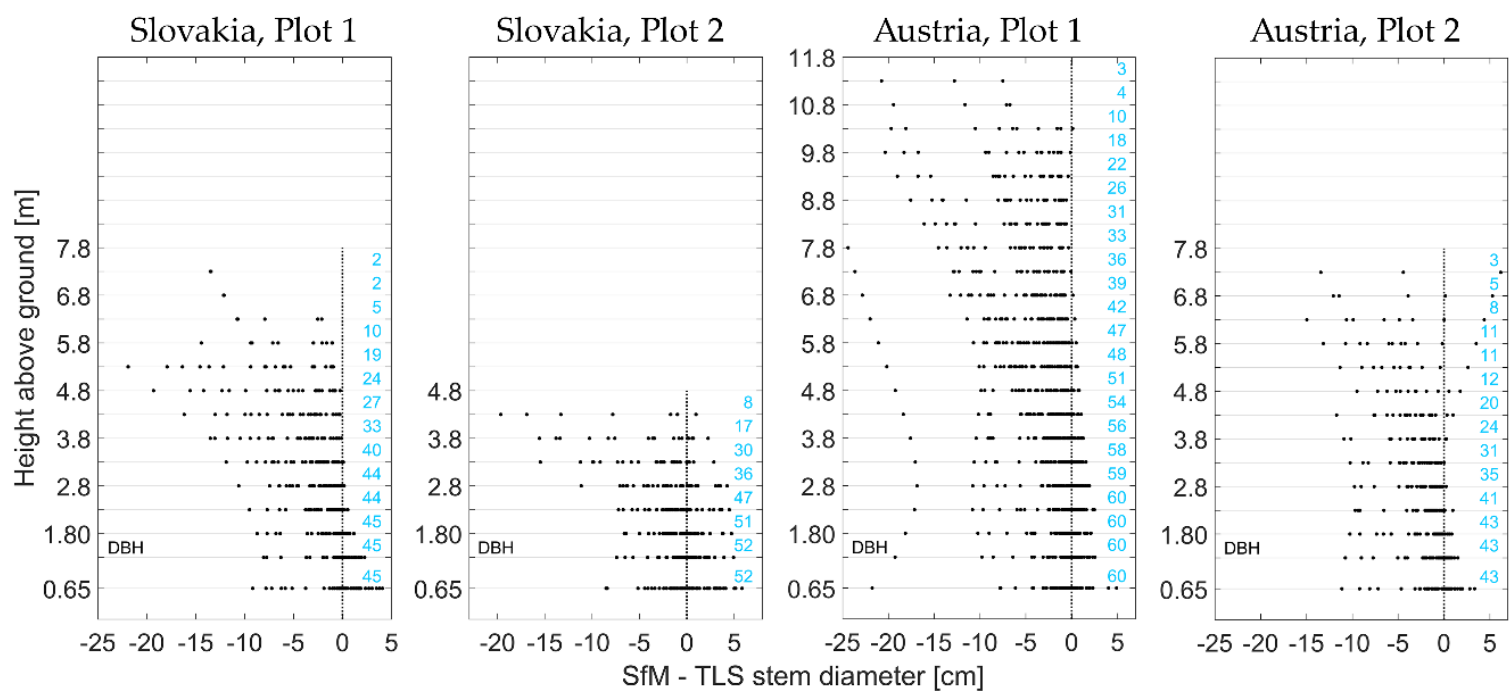

Figure 8. For each forest plot, the difference of the stem curve between SfM and TLS. In light blue, the number of estimated diameters for each height above the ground is shown.

\subsection{Comparison of Time and Resource Requirements}

The main challenge lies in the speed of data acquisition [5]. In Table 7, we report the acquisition times for collecting the images and scans and for measuring the reference data. Partially, the SfM and TLS surveys were done concurrently. To avoid the capture of people, data capture hence had to be interrupted and resumed, and these standby times have been estimated and subtracted. The time to collect the images following our method (i.e., the photographic path with tripod) is almost the same as field measurements and TLS data acquisition, with the exception of plot 1 in Slovakia, which was classified as easy. In fact, for the other forest plots the steepness of the areas (plots 2 in Slovakia and Austria), the dimension and complexity of the forests have required about $2 \mathrm{~h}$ using the tripod.

Determining the costs to acquire the field inventory in comparison to SfM photogrammetry and TLS is not straightforward, because the costs vary according to the equipment, the required measurements, the expertise, the survey settings, and the complexity of the forest plot structure. The low costs of the photogrammetric equipment together with the possibility to use open-source SfM software is definitely a plus in favour of SfM photogrammetry. Perhaps the most serious disadvantage 
of this method is the heavy computation time (Table 7), which is directly related to the resolution and number of photographs taken, the processing parameters (e.g., the number of key and tie points), and most of all the computer hardware [52]. However, it is worth noting that the computation time for the image orientation and dense image matching does not require any user interaction. In contrast, the identification of targets in the images might require some hours of user work if coded targets are not used, whose centres can be detected automatically by the software.

All SfM datasets presented in this work were processed with the same computer and with the same parameters in PhotoScan (see Figure 3, Section 3.4.2). However, some tests were performed to evaluate the impact of the parameters and computer performance on the computation time. The maximum number of automatically detected key and tie points affects the image orientation processing time, as well as the performance of the image orientation as reported by [42]. The latter aspect was not investigated in our test, but the image orientation was completed in about $7 \mathrm{~h}$ and $40 \mathrm{~min}$ by setting the limits to 100,000 and 60,000 for the key and tie points, respectively (Table 7, Slovakia plot 1), whereas the orientation time decreased to $2 \mathrm{~h}$ and $45 \mathrm{~min}$ when the limits were set to 40,000 and 4000 (i.e., the default settings). Generally, the dense image matching step is particularly computationally intensive, but the time to generate the dense point cloud significantly increases according to the image resolution and the size of the bounding box. As shown in Table 7, the dense image matching for the small plot in Austria (plot 2) took less time than for the larger plot in Austria (plot 1), despite the larger number of images. Nevertheless, the processing time of the SfM workflow notably changes according to the computer characteristics. We computed the dense image matching of the largest dataset (Slovakia, plot 2) with another computer with lower performance and it required approximately 85 instead of $22 \mathrm{~h}$.

Table 7. Approximate times needed for data acquisition and processing for each survey methodology.

\begin{tabular}{|c|c|c|c|c|c|c|c|}
\hline \multicolumn{8}{|c|}{ Time Survey \& Processing } \\
\hline \multirow[b]{2}{*}{ Study Plot } & \multicolumn{3}{|c|}{ SfM } & \multicolumn{2}{|c|}{ TLS } & \multicolumn{2}{|c|}{ Reference } \\
\hline & $\begin{array}{l}\text { Image Acqu. } \\
\text { (No. Photos) }\end{array}$ & Orientation & $\begin{array}{l}\text { Dense } \\
\text { Image } \\
\text { Matching }\end{array}$ & $\begin{array}{l}\text { Scan } \\
\text { Acqu. }\end{array}$ & $\begin{array}{c}\text { Scan } \\
\text { Registration } \\
\text { \& Post-Proc. }\end{array}$ & DBH & $\begin{array}{c}\text { Tree } \\
\text { Location }\end{array}$ \\
\hline Slovakia, Plot 1 & $30^{\prime}(338)$ & $7 \mathrm{~h} 40^{\prime}$ & $9 \mathrm{~h} 20^{\prime}$ & $2 \mathrm{~h} 20^{\prime}$ & $3 \mathrm{~h}$ & $1 \mathrm{~h}$ & $2 \mathrm{~h}$ \\
\hline Slovakia, Plot 2 & $2 \mathrm{~h}(775)$ & $30 \mathrm{~h} 10^{\prime}$ & $22 \mathrm{~h} 10^{\prime}$ & $1 \mathrm{~h} 10^{\prime}$ & $3 \mathrm{~h}$ & $1.5 \mathrm{~h}$ & $3 \mathrm{~h}$ \\
\hline Austria, Plot 1 & 2 h (531) & $17 \mathrm{~h} 20^{\prime}$ & 33 h $30^{\prime}$ & $1 \mathrm{~h} 45^{\prime}$ & $2.5 \mathrm{~h}$ & $1 \mathrm{~h}$ & $2.5 \mathrm{~h}$ \\
\hline Austria, Plot 2 & $1 \mathrm{~h} 30^{\prime}$ (632) & $23 \mathrm{~h} 30^{\prime}$ & $18 \mathrm{~h} 10^{\prime}$ & $3 \mathrm{~h} 30^{\prime}$ & $2 \mathrm{~h}$ & $1.5 \mathrm{~h}$ & $2.5 \mathrm{~h}$ \\
\hline
\end{tabular}

\section{Discussion}

Our motivation to apply terrestrial SfM photogrammetry on forest plots was to evaluate its feasibility and efficiency for deriving the tree positions, DBHs, and the lower parts of the stem curves in support of forest inventory. In fact, the lack of efficient inventory tools is an old and well-known problem in forestry, which still persists today [6]. TLS currently represents the most accurate and precise method for deriving these attributes at the plot level. Particularly the derivation of tree stem curves from TLS and mobile laser scanning data is a current research focus [53]. However, due to the cost and the acquisition and processing time of multiple scans, which are needed to mitigate the occlusion effect, and then to provide almost full coverage of the plot $[11,17,54]$, forestry researchers are looking for alternative methods. In this respect, terrestrial SfM photogrammetry offers a low-cost and potentially fast solution, due to the high portability of a camera for deriving a 3D point cloud of forest plot. Furthermore, contrary to TLS data, images are saved in a standard format and one can use vendor independent processing software, therefore, more flexibility on choosing the processing software (even open source solutions).

Liang et al. [17] were the first to investigate the feasibility of terrestrial SfM point clouds on forest plots in comparison with those from TLS, followed by a few others [39-43]. 
A highlight of our investigation is that we evaluated the feasibility of terrestrial SfM on four different forest plots, which were classified as easy, medium and complex, according to their size, density, and amount of understory. To date, terrestrial SfM photogrammetry for forest plot inventory is still in the early stages of development, because natural forests are challenging environments, and hence, terrestrial SfM photogrammetry can be applied successfully only if certain conditions are met. In short, these conditions require sufficient qualities of image content and image orientation, the presence of moderately convergent images that cover all stems to a large extent, and the availability of information to scale and level the resulting point cloud. In detail, many factors affect the success of SfM and the quality of its results, like intersection angles, camera baselines i.e., distances between consecutive images, the number of images, image overlap, resolution and quality, the distribution and distinctiveness of local features in every image, the accuracy of the information used for scaling and levelling, and the environmental conditions (e.g., lighting and wind). Generally, the precision of SfM point coordinates decreases with their distance from the photographer's path [17]. All these mentioned factors are adequately explained by [39].

The optimum imaging network and hence the photographer's path depends on the complexity of the forest plot structure (e.g., the distribution of trees, their stem diameters, and the presence of undergrowth vegetation), and on the required accuracy of forest parameters to be estimated. The acquisition method we propose consists of a basic configuration with extensions to be used on complex forest plots and for achieving highest accuracies. It combines the photographic paths tested by $[39,42]$. The basic configuration consists of a circular path around the plot, pointing the camera inwards, followed by another circular path in its interior, pointing the camera outwards (Figure A1). For complex forest plots, this standard path needs to be augmented with two perpendicular straight lines across the plot, as suggested by [42]. This extension was used on one plot (Slovakia plot 2), due to its high forest density. As outlined above, the success and quality of SfM for forest plot inventory depends on many factors, and therefore, there is no universally applicable, optimum solution for image acquisition. However, our proposed configuration constitutes a good compromise for capturing many redundant photos within a short time, ensuring good imaging network geometry, complete coverage, adequate intersection angles and sufficient similarity in overlapping images to automatically match homologous points in them. Our configuration has proven to work under diverse conditions and hence can be used in the sense of a scientific protocol.

For the most complex forest plot (Slovakia plot 2), only $79 \%$ of reference stems were detected by TLS (and 65\% by SfM, Table 4). This shows that, also for TLS, the number of scan positions, which may need to be high to mitigate occlusions, is a trade-off between the costs of field work (i.e., acquisition time) and the data quality [55]. Generally, complete (horizontal) coverage is more relevant than point density for stem reconstruction, but most often, completeness is correlated with point density. In our approach, the point clouds used to reconstruct the trees were subsampled to $2 \mathrm{~cm}$, which might harm the completeness and consequently affect the successful reconstruction of thin trees.

Using our acquisition method, all the images were properly oriented with millimetre accuracy (Table 3), without manual interventions. For automatic image orientation to be successful, overlapping images must feature sufficiently similar contents. Hence, tree stems should either not be pictured from close by, or the base line should be shortened. Figure 9 shows an image sequence where this rule was not met.

The images in this study were acquired in landscape mode with the focus on ground reconstruction, stem detection and the estimation of DBHs, rather than tree heights and stem curves. The accuracy and completeness of the SfM-derived DTMs are sufficient to independently estimate the DBH from the SfM point cloud. 

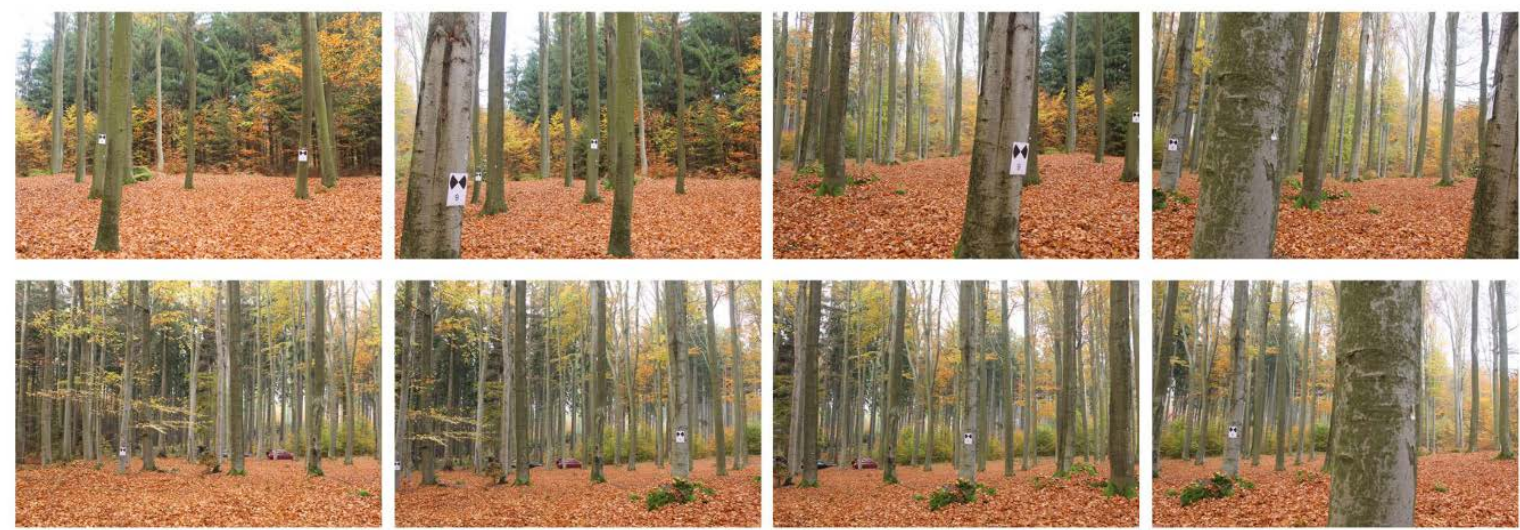

Figure 9. Sub-optimal image sequence for successful automatic image orientation.

One important aspect of SfM (and TLS) point clouds is that the location of trees, which is usually not measured in field inventories to avoid the costs, can be provided automatically using appropriate software. For the DBH and tree locations, the required level of accuracy is up to $2 \mathrm{~cm}$ and $0.5-2 \mathrm{~m}$, respectively [12]. In this respect, our results show that terrestrial SfM photogrammetry can meet these requirements. The number of detected stems varies based on the forest plot complexity, the method compared to, i.e., TLS or field inventory, and the stem diameter. Young trees might be partially missed at breast height in the SfM point cloud (Figure 6), which directly affects tree detection since it is done at this height in our approach. Similarly, trees imaged only from far away use to be represented by sparse and noisy points, and are more likely to be omitted [39]. Furthermore, noise filtering of the point clouds may negatively affect trees already represented only partially by further reducing their density and completeness. Consequently, stems are difficult to separate, especially bent ones (Figure 6). However, as another advantage over TLS, the availability of photos and coloured point clouds eases the verification of automatic stem detection. Furthermore, the colour attributes of SfM point clouds can be used to identify different components of the forest plot model i.e., leaves, branches, and irrelevant noise, as pointed out by [7] and tree species classification might be easier than with TLS data. Regarding DBH estimation, our results suggest that the differences between the mean values provided by the three applied methods are insignificant, and that the obtained accuracies were largely affected by the method used to automatically identify corresponding trees in the different data sets.

As demonstrated by recent studies, the accuracy of SfM results also varies with the resolution of the image sensor (e.g., video, mobile phone and SLR camera), the camera configuration (e.g., portrait, landscape), and the equipment used to support the camera (e.g., hand-held, measurement pole, tripod). Summarising the accuracies reported in the published studies, the tree detection rate ranges between $50 \%$ and $80 \%$ and DBH is estimated with an RMSE approximately between $1.5 \mathrm{~cm}$ and $6.0 \mathrm{~cm}$. Mokroš et al. [42] achieved the best results using a portrait camera orientation. In contrast, [39] found that results were optimal for landscape images, also adopted in this study. One limitation of using landscape images is that only the lower stem parts are captured, and stem modelling is consequently limited. Using our data, stem curves could be reconstructed reliably up to about $3 \mathrm{~m}$ above ground. The use of terrestrial SfM photogrammetry for deriving tree heights by capturing images at three different levels was tested by [40]. They conclude that accuracy decreases with tree height due to larger distances from the sensor (i.e., lower resolution at the object), lower point density because of lower image overlap, and increasing difficulty in distinguishing stem points.

A general observation is that images should be acquired according to the forest parameters of interest (basal area, tree diameter, tree height). However, acquiring multiple images, especially at different levels, requires multiple shutter releases, which can be time-consuming and labour-intensive. With the goal of shortening the acquisition time, the possibility to derive the stem curve from video frames was evaluated by [31]. They tested the method in a sparse forest, and they conclude that if blurred video frames were omitted, the differences in accuracy between results from video frames and 
still images are insignificant. Also, the need for short acquisition times of forest plot inventory data motivated our use of terrestrial SfM photogrammetry. Unfortunately, not all the published studies report the image acquisition and processing times. The acquisition time strongly depends on the photographic path, baseline, equipment (e.g., focal length), and the adopted approach to scale and level the point cloud. We used a tripod to ensure high image quality, with the drawback of a relatively long acquisition time. However, images acquired for SfM can be taken from a hand-held camera without a tripod [7], if lighting conditions are sufficient. Despite the use of a tripod, the time to collect the images is generally similar to the one of TLS and field inventory while for easy plots it is significantly lower. One drawback of our surveying approach is the use of artificial targets to scale and level the SfM point clouds, measured with a total station. While this is a standard approach in SfM, it reduces the portability of the entire system, and it increases the acquisition time per plot. To avoid the need for a total station, scale may be derived instead from distances between artificial targets or natural features measured with a measuring tape [17], and the levelling may be derived from plumb lines placed on the plot.

The longer computation times are a drawback of SfM photogrammetry, but they strongly depend on the computer hardware and processing parameters (see Section 4.3). The time required to identify the targets on a large image dataset can be greatly reduced by employing coded targets in the field that can automatically be detected by the software. The workflow to generate a SfM point cloud is highly automated (i.e., low requirements on user expertise) and easier than processing multiple TLS scans in the case of a dense forest plot.

Our results suggest that terrestrial SfM photogrammetry is suitable for deriving forest inventory parameters at the plot level in different forest environments. However, several questions remain to be answered. Open research questions concern the decrease in quality (i.e., accuracy and completeness) when increasing the baseline between the images (i.e., thinning the dataset), or when reducing the quality of the sensor (e.g., mobile phone), and quick, mobile, accurate ways to provide the information needed to scale and level the point clouds. Furthermore, for practical forest inventory, more investigations are needed about the influence of forest types and conditions (features on stems, leaf-off vs. leaf-on, and tree species) on DBH estimation and stem curve modelling. At this moment, the latter does not represent the main research focus for SfM, but it would be beneficial to explore the optimal acquisition method to derive at least the lower parts of the stem curve. Additionally, further work is needed to fully understand the implications of point density and noise filtering in the performance of automatic algorithms for deriving forest metrics from SfM point clouds. Also, further investigations are needed with respect to the algorithms used to automatically derive forest-related parameters from point clouds.

More broadly, as reported by [6], the current question is whether in situ 3D digitizing technologies can be promoted to the next level, in which tree- and plot-level attributes over large areas can be retrieved rapidly, accurately and cost-efficiently.

\section{Conclusions}

Plot-scale forest measurements can either be collected traditionally in a rather time-consuming tree-by-tree field inventory, or estimated by remote sensing techniques using LiDAR or SfM photogrammetry. The present study was designed to answer some prominent research questions regarding the advantages of applying terrestrial SfM photogrammetry in support of plot-scale forest inventory by (i) reconstructing plot point clouds under a considerable range of forest conditions and (ii) deriving accurate estimates of tree positions and DBHs from them. 
Based on our results, we answer the formulated research questions as follows.

(1) The proposed photographer's path and respective camera orientations are a reliable and strongly recommended method to ensure both short acquisition times and high-quality point clouds of forest plots under different forest conditions.

(2) The estimated accuracy of the camera orientations is within the range of a few millimetres and the vertical error of the DTMs is below $2 \mathrm{~cm}$ when compared to TLS.

(3) The percentage of detected trees compared with field inventories ranges between $65 \%$ and $98 \%$, and between $68 \%$ and $98 \%$ with respect to TLS. The missing trees can be visualized and manually identified in the coloured SfM point cloud.

(4) The average deviation of the DBHs per plot ranges between -2.07 and $-0.71 \mathrm{~cm}$ with respect to the caliper measurements, and it varies according to the complexity of the forest plot.

(5) The stem curve can be estimated reliably up to $3 \mathrm{~m}$ above ground, with an accuracy of better than $2 \mathrm{~cm}$ with respect to TLS, based on our image capture method.

The acquisition time for a forest plot ranges between around $30 \mathrm{~min}$ and $2 \mathrm{~h}$, depending on the forest plot size and complexity. This study emphasizes the suitability of terrestrial SfM photogrammetry in support of forest inventory measurements, and it provides an additional basis for future investigations to further improve the efficiency of the method.

Author Contributions: Conceptualization, L.P., M.H., and N.P.; methodology, L.P., W.K., M.W., D.W, and M.H..; data acquisition, L.P., W.K., M.W., M.K., J.T., P.S., M.H., and M.M.; software, L.P., M.W. and D.W.; formal analysis, L.P., W.K., M.W., J.T., and D.W.; investigation, L.P.; resources, M.H., N.P., M.M., and P.S.; data curation, L.P.; writing—original draft preparation, L.P.; writing—review and editing, M.M., W.K., D.W., P.S., M.W., M.K., J.T., M.H., and N.P.; visualization, L.P..; supervision, M.H. and N.P.; project administration, M.H.; funding acquisition, M.H and N.P.

Funding: This research was funded by Centre for International Cooperation \& Mobility (ICM) of the Austrian Agency for International Cooperation in Education and Research (OeAD-GmbH) through the project "Benchmarking of close-range photogrammetry methods for forestry applications", project identification number MULT_DR 04/2017. The Federal Ministry of Science, Research and Economy (BMWFW) provided the financial support.

Acknowledgments: The authors acknowledge the TU Wien University Library for financial support through its Open Access Funding Program.

Conflicts of Interest: The authors declare no conflict of interest. The funders had no role in the design of the study; in the collection, analyses, or interpretation of data; in the writing of the manuscript, or in the decision to publish the results.

\section{Appendix A}

Table A1. A comparison between measured DBH (Ref) and estimated DBH from SfM and TLS point cloud. Ref $\mathrm{SfM}_{\mathrm{SP}}$ and $\operatorname{Ref}_{\mathrm{TLS}}$ indicate the trees measured by caliper that correspond to the SfM and TLS DBH estimates, respectively.

\begin{tabular}{|c|c|c|c|c|c|c|c|c|c|c|c|c|c|c|c|c|}
\hline \multicolumn{17}{|c|}{$\mathrm{DBH}[\mathrm{cm}]$} \\
\hline \multirow[b]{2}{*}{ Data } & \multicolumn{4}{|c|}{ Slovakia Plot 1} & \multicolumn{4}{|c|}{ Slovakia Plot 2} & \multicolumn{4}{|c|}{ Austria Plot 1} & \multicolumn{4}{|c|}{ Austria Plot 2} \\
\hline & $\begin{array}{l}\text { No. } \\
\text { Trees }\end{array}$ & Min-Max & Mean & $\sigma$ & $\begin{array}{l}\text { No. } \\
\text { Trees }\end{array}$ & Min-Max & Mean & $\sigma$ & $\begin{array}{l}\text { No. } \\
\text { Trees }\end{array}$ & Min-Max & Mean & $\sigma$ & $\begin{array}{l}\text { No. } \\
\text { Trees }\end{array}$ & Min-Max & Mean & $\sigma$ \\
\hline Ref & 46 & $9.7-41.9$ & 30.7 & 7.1 & 110 & $6.4-58.9$ & 22.6 & 13.1 & 66 & $9.3-63.9$ & 29.8 & 14.3 & 47 & $5.7-40.8$ & 24.2 & 11.4 \\
\hline \multirow{2}{*}{$\begin{array}{c}\operatorname{Ref}_{\mathrm{SfM}} \\
\text { SfM }\end{array}$} & \multirow{2}{*}{45} & $16.0-41.9$ & 31.1 & 6.4 & \multirow{2}{*}{72} & $6.6-58.9$ & 24.7 & 13.0 & \multirow{2}{*}{55} & $12.0-63.9$ & 33.4 & 13.0 & \multirow{2}{*}{43} & $6.6-40.8$ & 25.8 & 10.5 \\
\hline & & $13.6-42.1$ & 30.4 & 6.7 & & $6.6-57.6$ & 24.3 & 13.6 & & $5.12-60.8$ & 31.3 & 13.5 & & $6.6-40.1$ & 25.0 & 10.3 \\
\hline
\end{tabular}



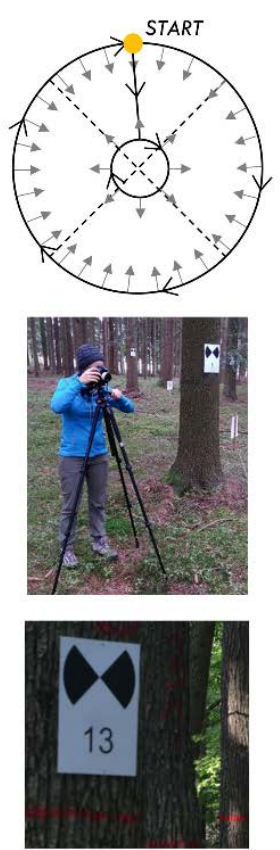

Slovakia, Plot 1

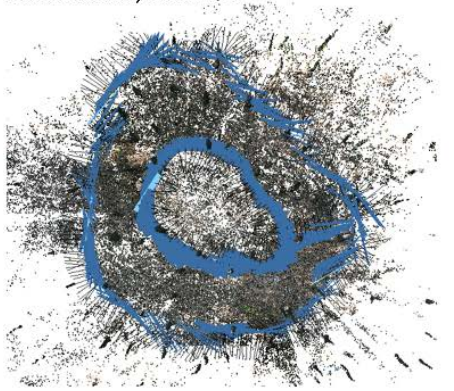

Austria, Plot 1

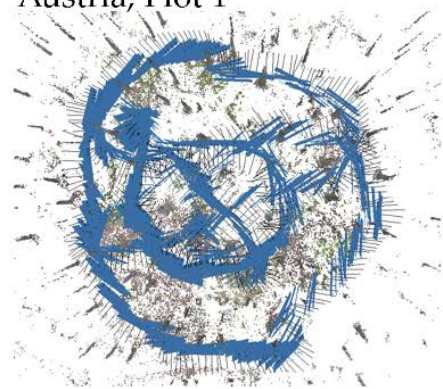

Slovakia, Plot 2

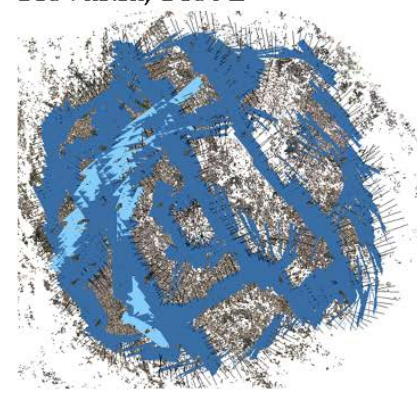

Austria, Plot 2

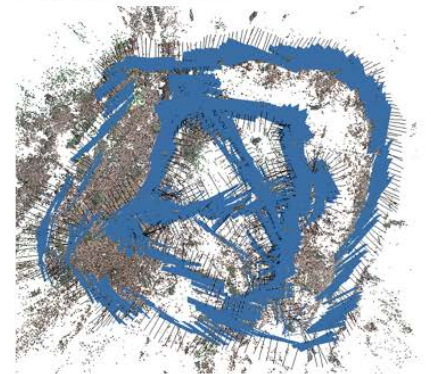

Figure A1. On the left, a schematic illustration of the photographic path, and a picture illustrating the image acquisition in the forest plot and the targets used for scaling definition and accuracy estimation of the camera orientation. On the right, the camera orientation and the tie points generated in PhotoScan for each forest plot.

(a) Slovakia, Plot 1
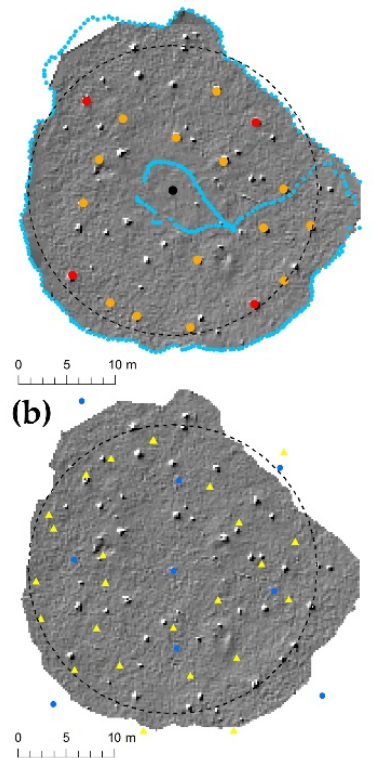

Slovakia, Plot 2

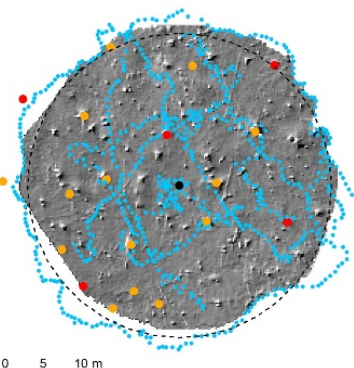

5 in

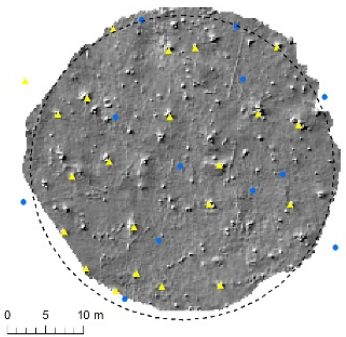

Austria, Plot 1

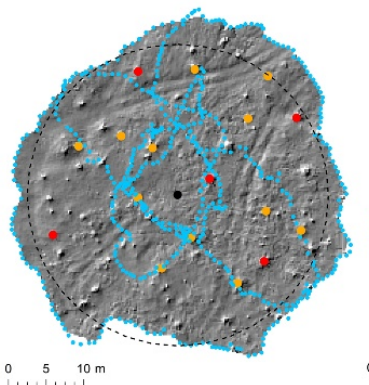

$\stackrel{5}{100 m}$
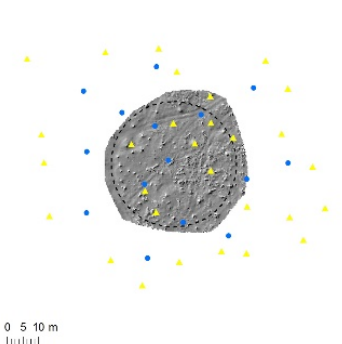

Austria, Plot 2
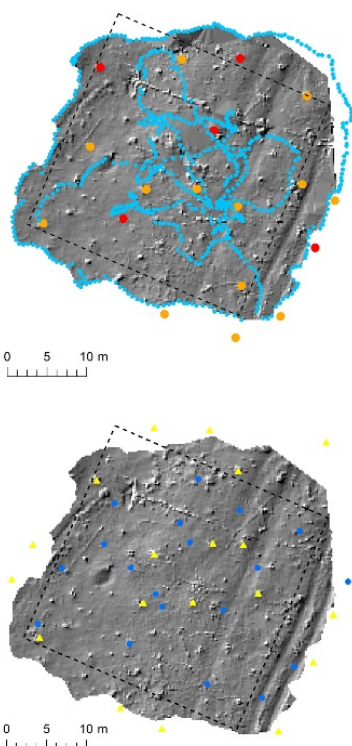

- GCPs (SfM) • CPs (SfM) - Camera positions - TLS scan positions $\triangle$ TLS targets

Figure A2. For each forest plot, the hillshade DTM generated from the interpolation of (a) the SfM and (b) the TLS point cloud. On the SfM hillshade, we overlay the camera location (light blue dots), the GCPs (red dots) and CPs (orange dots) while in the TLS hillshade the scan positions (blue dots) and the TLS targets (red dots) are reported. The black dot in the SfM hillshade indicates the centre of the plot and the black dash line approximates the plot boundary. 

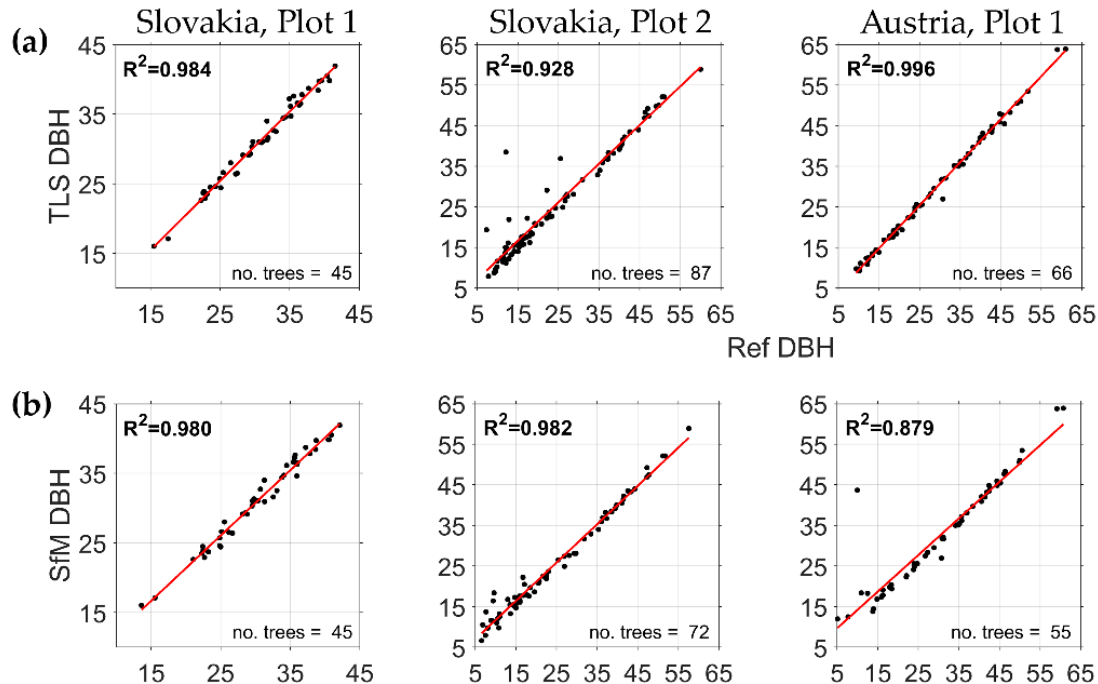
Ref DBH

(1)

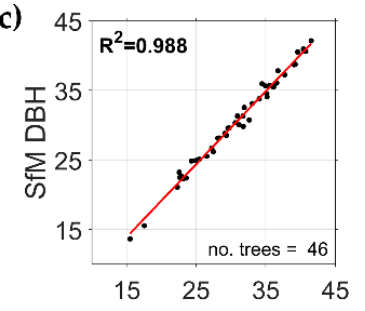

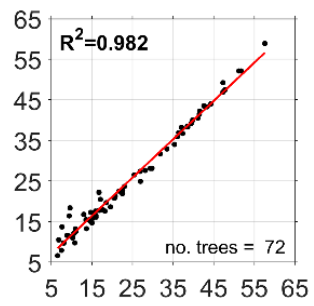
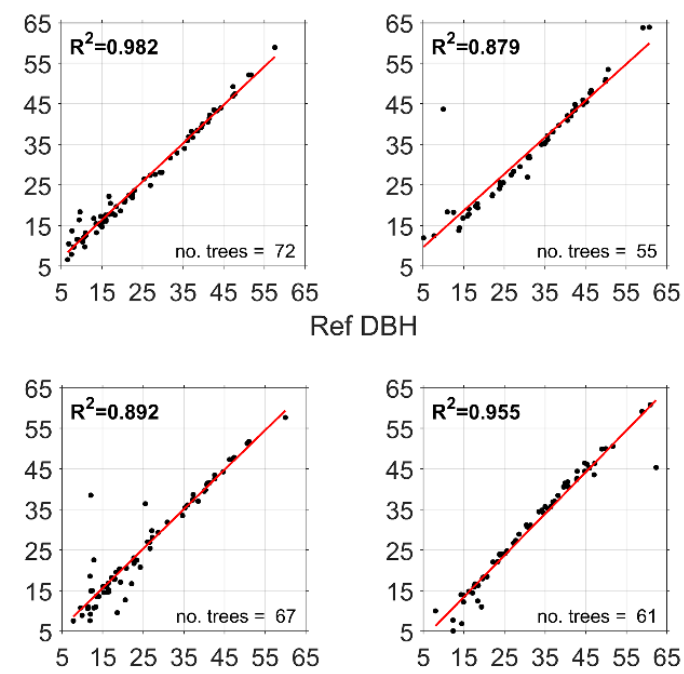

Ref DBH

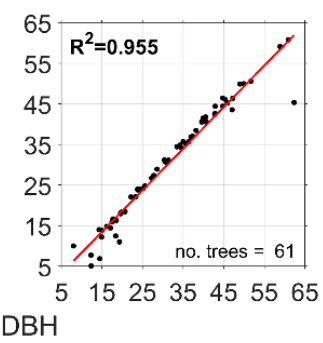

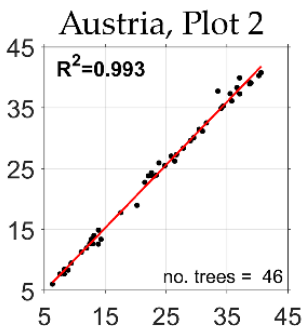
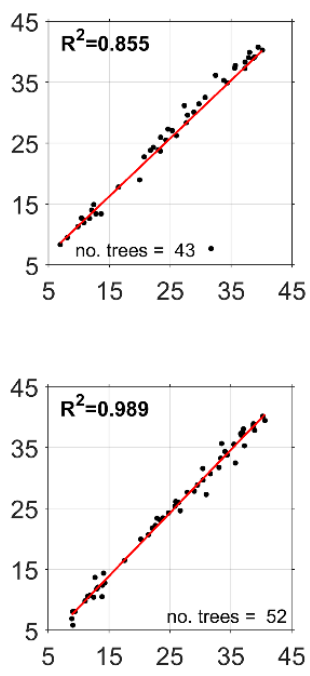

Figure A3. For all the forest plots, the scatterplot of the DBH estimates from (a) TLS and (b) SfM with respect to the caliper measurements and (c) from the SfM with respect to the TLS estimates.

(a)

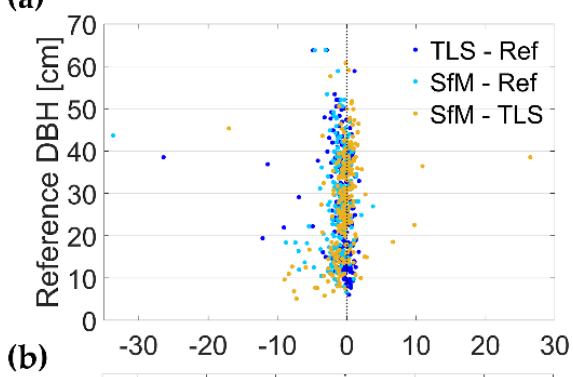

(b)

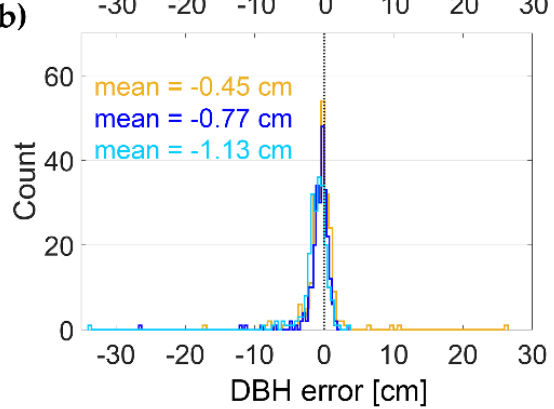

(c)

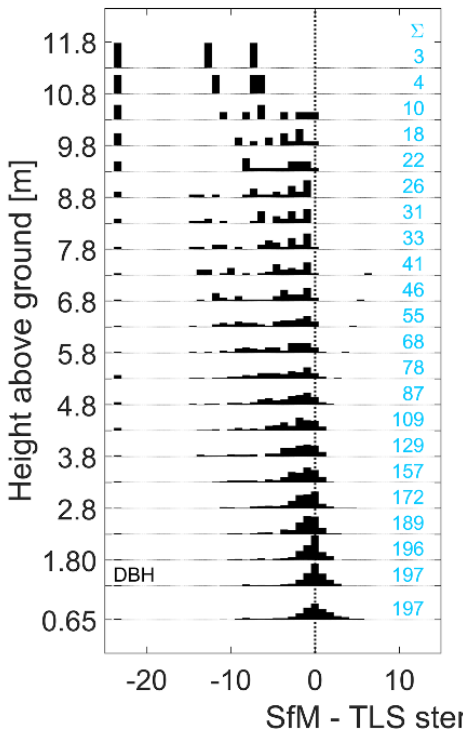

(d)

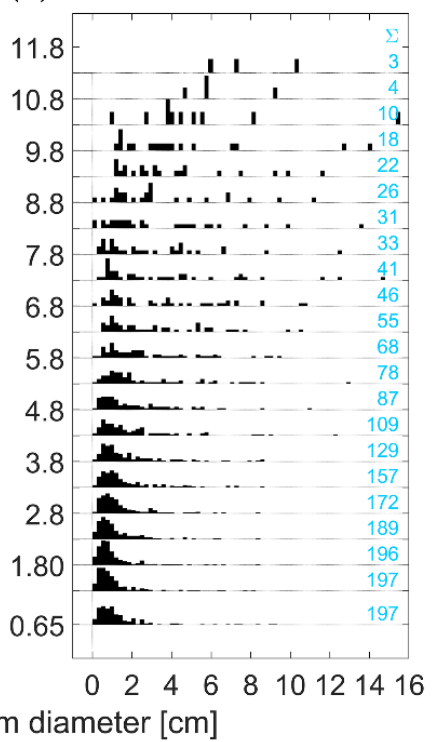

Figure A4. For all the forest plots, the DBH errors for SfM and TLS in comparison to the reference measurements show as (a) scatterplot and (b) histogram. The histogram for each height above the ground of (c) the SfM stem diameter error and (d) the offset of the stem centre between SfM and TLS. In light blue, the total number of estimated diameters for every height above the ground. 
Table A2. Median SfM stem curve error.

\begin{tabular}{|c|c|c|c|c|c|c|c|c|c|c|c|c|}
\hline \multicolumn{13}{|c|}{ Stem Curve Error $[\mathrm{cm}]$ SfM vs. TLS } \\
\hline \multirow{3}{*}{ Study Areas } & \multicolumn{6}{|c|}{ Median Stem Diameter } & \multicolumn{6}{|c|}{ Median Length of Stem Centre Offset } \\
\hline & \multicolumn{6}{|c|}{ Height above Ground [m] } & \multicolumn{6}{|c|}{ Height above Ground [m] } \\
\hline & 0.65 & 1.30 & 1.80 & 2.30 & 2.80 & $>2.80$ & 0.65 & 1.30 & 1.80 & 2.30 & 2.80 & $>2.80$ \\
\hline Slovakia Plot 1 & 0.19 & 0.09 & -0.30 & -0.90 & -1.82 & -3.75 & 0.77 & 0.60 & 0.70 & 0.90 & 1.10 & 1.82 \\
\hline Slovak & 0.39 & 0.21 & -0.55 & -1.26 & -1.83 & -2.41 & 1.16 & 0.86 & 0.93 & 0.95 & 1.20 & 2.12 \\
\hline Austria Plot 1 & -0.47 & -0.17 & -0.24 & -0.25 & -0.42 & -2.61 & 0.85 & 0.72 & 0.74 & 0.70 & 0.78 & 1.43 \\
\hline Austria Plot 2 & -0.61 & -0.38 & -0.88 & -1.31 & -1.51 & -3.31 & 1.30 & 0.99 & 0.79 & 0.73 & 1.10 & 1.77 \\
\hline
\end{tabular}

\section{References}

1. Ridder, R.M. Global Forest Resources Assessment 2010: Options and Recommendations for a Global Remote Sensing Survey of Forests. FAO Forest Resource Assessment. Programme Work. 2007, p. 141. Available online: http://www.fao.org/3/a-ai074e.pdf (accessed on 19 April 2019).

2. Van Laar, A.; Akça, A. Forest Mensuration; Springer: Dordrecht, The Netherlands, 2007; Volume 13, pp. 360-383.

3. Newnham, G.J.; Armston, J.D.; Calders, K.; Disney, M.I.; Lovell, J.L.; Schaaf, C.B.; Strahler, A.H.; Danson, F.M. Terrestrial laser scanning for plot-scale forest measurement. Curr. For. Rep. 2015, 1, 239-251. [CrossRef]

4. Wallace, L.; Lucieer, A.; Malenovský, Z.; Turner, D.; Vopěnka, P. Assessment of forest structure using two UAV techniques: A comparison of airborne laser scanning and structure from motion (SfM) point clouds. Forests 2016, 7, 62. [CrossRef]

5. Liang, X.; Kukko, A.; Hyyppä, J.; Lehtomäki, M.; Pyörälä, J.; Yu, X.; Kaartinen, H.; Jaakkola, A.; Wang, Y. In-situ measurements from mobile platforms: An emerging approach to address the old challenges associated with forest inventories. ISPRS J. Photogramm. Remote Sens. 2018, 143, 97-107. [CrossRef]

6. Liang, X.; Hyyppä, J.; Kaartinen, H.; Lehtomäki, M.; Pyörälä, J.; Pfeifer, N.; Holopainen, M.; Brolly, G.; Francesco, P.; Hackenberg, J.; et al. International benchmarking of terrestrial laser scanning approaches for forest inventories. ISPRS J. Photogramm. Remote Sens. 2018, 144, 137-179. [CrossRef]

7. Miller, J.M. Estimation of Individual Tree Metrics Using Structure-From-Motion Photogrammetry; University of Canterbury: Christchurch, UK, 2015; 99p.

8. Latifi, H.; Fassnacht, F.E.; Müller, J.; Tharani, A.; Dech, S.; Heurich, M. Forest inventories by LiDAR data: A comparison of single tree segmentation and metric-based methods for inventories of a heterogeneous temperate forest. Int. J. Appl. Earth Obs. Geoinf. 2015, 42, 162-174. [CrossRef]

9. Liang, X.; Kankare, V.; Yu, X.; Hyyppä, J.; Holopainen, M. Automatic stem curve measurement using terrestrial laser scanning. IEEE Trans. Geosci. Remote Sens. 2014, 52, 1739-1748. [CrossRef]

10. Yu, X.; Liang, X.; Hyyppä, J.; Kankare, V.; Vastaranta, M.; Holopainen, M. Stem biomass estimation based on stem reconstruction from terrestrial laser scanning point clouds. Remote Sens. Lett. 2013, 4, 344-353. [CrossRef]

11. Kankare, V.; Holopainen, M.; Vastaranta, M.; Puttonen, E.; Yu, X.; Hyyppä, J.; Vaaja, M.; Hyyppä, H.; Alho, P. Individual tree biomass estimation using terrestrial laser scanning. ISPRS J. Photogramm. Remote Sens. 2013, 75, 64-75. [CrossRef]

12. Liang, X.; Kankare, V.; Hyyppä, J.; Wang, Y.; Kukko, A.; Haggrén, H.; Yu, X.; Kaartinen, H.; Jaakkola, A.; Guan, F; et al. Terrestrial laser scanning in forest inventories. ISPRS J. Photogramm. Remote Sens. 2016, 115, 63-77. [CrossRef]

13. Calders, K.; Newnham, G.; Burt, A.; Murphy, S.; Raumonen, P.; Herold, M.; Culvenor, D.; Avitabile, V.; Disney, M.; Armston, J.; et al. Nondestructive estimates of above-ground biomass using terrestrial laser scanning. Methods Ecol. Evol. 2015, 6, 198-208. [CrossRef]

14. Hauglin, M.; Astrup, R.; Gobakken, T.; Næsset, E. Estimating single-tree branch biomass of Norway spruce with terrestrial laser scanning using voxel-based and crown dimension features. Scand. J. For. Res. 2013, 28, 456-469. [CrossRef]

15. Wagner, B.; Ginzler, C.; Bürgi, A.; Santini, S.; Gärtner, H. An annually-resolved stem growth tool based on 3D laser scans and 2D tree-ring data. Trees 2018, 32, 125-136. [CrossRef] 
16. Smith, A.; Astrup, R.; Raumonen, P.; Liski, J.; Krooks, A.; Kaasalainen, S.; Åkerblom, M.; Kaasalainen, M. Tree root system characterization and volume estimation by terrestrial laser scanning and quantitative structure modeling. Forests 2014, 5, 3274-3294. [CrossRef]

17. Liang, X.; Jaakkola, A.; Wang, Y.; Hyyppä, J.; Honkavaara, E.; Liu, J.; Kaartinen, H. The use of a hand-held camera for individual tree 3D mapping in forest sample plots. Remote Sens. 2014, 6, 6587-6603. [CrossRef]

18. Wang, D.; Hollaus, M.; Puttonen, E.; Pfeifer, N. Automatic and self-adaptive stem reconstruction in landslide-affected forests. Remote Sens. 2016, 8, 974. [CrossRef]

19. White, J.C.; Coops, N.C.; Wulder, M.A.; Vastaranta, M.; Hilker, T.; Tompalski, P. Remote sensing technologies for enhancing forest inventories: A review. Can. J. Remote Sens. 2016, 42, 619-641. [CrossRef]

20. Rönnholm, P.; Liang, X.; Kukko, A.; Jaakkola, A.; Hyyppä, J. Quality analysis and correction of mobile backpack laser scanning data. ISPRS Ann. Photogramm. Remote Sens. Spat. Inf. Sci. 2016, 3, 41-47. [CrossRef]

21. Batista Campos, M.; Garcia Tommaselli, A.M.; Honkavaara, E.; dos Santos Prol, F.; Kaartinen, H.; El Issaoui, A.; Hakala, T. A Backpack-Mounted Omnidirectional Camera with Off-the-Shelf Navigation Sensors for Mobile Terrestrial Mapping: Development and Forest Application. Sensors 2018, 18, 14248220.

22. Ryding, J.; Williams, E.; Smith, M.; Eichhorn, M. Assessing handheld mobile laser scanners for forest surveys. Remote Sens. 2015, 7, 1095-1111. [CrossRef]

23. Bauwens, S.; Bartholomeus, H.; Calders, K.; Lejeune, P. Forest inventory with terrestrial LiDAR: A comparison of static and hand-held mobile laser scanning. Forests 2016, 7, 127. [CrossRef]

24. Marselis, S.M.; Yebra, M.; Jovanovic, T.; van Dijk, A.I.J.M. Deriving comprehen- sive forest structure information from mobile laser scanning observations using au- tomated point cloud classification. Environ. Modell. Software 2016, 82, 142-151.

25. Forsman, M.; Holmgren, J.; Olofsson, K. Tree stem diameter estimation from mobile laser scanning using line-wise intensity-based clustering. Forests 2016, 7, 206. [CrossRef]

26. Čerňava, J.; Tuček, J.; Koreň, M.; Mokroš, M. Estimation of diameter at breast height from mobile laser scanning data collected under a heavy forest canopy. J. For. Sci. 2017, 63, 433-441.

27. Oveland, I.; Hauglin, M.; Gobakken, T.; Næsset, E.; Maalen-Johansen, I. Automatic estimation of tree position and stem diameter using a moving terrestrial laser scanner. Remote Sens. 2017, 9, 350. [CrossRef]

28. Forsman, M.; Börlin, N.; Holmgren, J. Estimation of Tree Stem Attributes Using Terrestrial Photogrammetry with a Camera Rig. Forests 2016, 7, 61. [CrossRef]

29. Tseng, Y.H.; Chen, Y.C.; Lin, K.Y. Bundle Adjustment of Spherical Images Acquired with a Portable Panoramic Image Mapping System (PPIMS). Photogramm. Eng. Remote Sens. 2016, 82, 935-943. [CrossRef]

30. Dick, A.R.; Kershaw, J.A., Jr.; MacLean, D.A. Spatial tree mapping using photography. North. J. Appl. For. 2010, 27, 68-74.

31. Itakura, K.; Hosoi, F. Estimation of tree structure parameters from video frames with removal of blurred images using machine learning. J. Agric. Meteorol. 2018, 74, 154-161. [CrossRef]

32. Morgenroth, J.; Gómez, C. Assessment of tree structure using a 3D image analysis technique-A proof of concept. Urban For. Urban Green. 2014, 13, 198-203. [CrossRef]

33. Miller, J.; Morgenroth, J.; Gomez, C. 3D modelling of individual trees using a handheld camera: Accuracy of height, diameter and volume estimates. Urban For. Urban Green. 2015, 14, 932-940. [CrossRef]

34. Huang, H.; Zhang, H.; Chen, C.; Tang, L. Three-dimensional digitization of the arid land plant Haloxylon ammodendron using a consumer-grade camera. Ecol. Evol. 2018, 8, 5891-5899. [CrossRef] [PubMed]

35. Surový, P.; Yoshimoto, A.; Panagiotidis, D. Accuracy of reconstruction of the tree stem surface using terrestrial close-range photogrammetry. Remote Sens. 2016, 8, 123. [CrossRef]

36. Bauwens, S.; Fayolle, A.; Gourlet-Fleury, S.; Ndjele, L.M.; Mengal, C.; Lejeune, P. Terrestrial photogrammetry: A non-destructive method for modelling irregularly shaped tropical tree trunks. Methods Ecol. Evol. 2017, 8, 460-471. [CrossRef]

37. Berveglieri, A.; Tommaselli, A.; Liang, X.; Honkavaara, E. Photogrammetric measurement of tree stems from vertical fisheye images. Scand. J. For. Res. 2017, 32, 737-747. [CrossRef]

38. Mokroš, M.; Výbošt'ok, J.; Tomaštík, J.; Grznárová, A.; Valent, P.; Slavík, M.; Merganič, J. High Precision Individual Tree Diameter and Perimeter Estimation from Close-Range Photogrammetry. Forests 2018, 9, 696. [CrossRef] 
39. Liang, X.; Wang, Y.; Jaakkola, A.; Kukko, A.; Kaartinen, H.; Hyyppä, J.; Honkavaara, E.; Liu, J. Forest data collection using terrestrial image-based point clouds from a handheld camera compared to terrestrial and personal laser scanning. IEEE Trans. Geosci. Remote Sens. 2015, 53, 5117-5132. [CrossRef]

40. Panagiotidis, D.; Surový, P.; Kuželka, K. Accuracy of Structure from Motion models in comparison with terrestrial laser scanner for the analysis of DBH and height influence on error behaviour. J. For. Sci. 2016, 62, 357-365. [CrossRef]

41. Mikita, T.; Janata, P.; Surový, P. Forest stand inventory based on combined aerial and terrestrial close-range photogrammetry. Forests 2016, 7, 165. [CrossRef]

42. Mokroš, M.; Liang, X.; Surový, P.; Valent, P.; Čerňava, J.; Chudý, F.; Merganič, J. Evaluation of close-range photogrammetry image collection methods for estimating tree diameters. ISPRS Int. J. Geo-Inf. 2018, 7, 93. [CrossRef]

43. Liu, J.; Feng, Z.; Yang, L.; Mannan, A.; Khan, T.; Zhao, Z.; Cheng, Z. Extraction of Sample Plot Parameters from 3D Point Cloud Reconstruction Based on Combined RTK and CCD Continuous Photography. Remote Sens. 2018, 10, 1299. [CrossRef]

44. Micheletti, N.; Chandler, J.H.; Lane, S.N. Structure from Motion (SFM) Photogrammetry. In Geomorphological Techniques; Clarke, L.E., Nield, J.M., Eds.; British Society for Geomorphology: London, UK, 2015; Chapter 2, Section 2.2; pp. 1-12.

45. CloudCompare Wiki. Available online: https://www.cloudcompare.org/doc/wiki/index.php?title=SOR_filter (accessed on 1 October 2018).

46. Pfeifer, N.; Mandlburger, G. LiDAR data filtering and DTM generation. In Topographic Laser Ranging and Scanning: Principles and Processing; CRC Press: Boca Raton, FL, USA, 2009; pp. 307-334.

47. Wang, D.; Hollaus, M.; Schmaltz, E.; Wieser, M.; Reifeltshammer, D.; Pfeifer, N. Tree stem shapes derived from TLS data as an indicator for shallow landslides. Procedia Earth Planet. Sci. 2016, 16, 185-194. [CrossRef]

48. Kraus, K.; Pfeifer, N. Determination of terrain models in wooded areas with airborne laser scanner data. ISPRS J. Photogramm. Remote Sens. 1998, 53, 193-203. [CrossRef]

49. Pfeifer, N.; Mandlburger, G.; Otepka, J.; Karel, W. OPALS-A framework for Airborne Laser Scanning data analysis. Comput. Environ. Urban Syst. 2014, 45, 125-136. [CrossRef]

50. Wang, D.; Brunner, J.; Ma, Z.; Lu, H.; Hollaus, M.; Pang, Y.; Pfeifer, N. Separating Tree Photosynthetic and Non-Photosynthetic Components from Point Cloud Data Using Dynamic Segment Merging. Forests 2018, 9, 252. [CrossRef]

51. Cheng, Y. Mean shift, mode seeking, and clustering. IEEE Trans. Pattern Anal. Mach. Intell. 1995, 17, 790-799. [CrossRef]

52. Piermattei, L.; Carturan, L.; Guarnieri, A. Use of terrestrial photogrammetry based on structure-from-motion for mass balance estimation of a small glacier in the Italian alps. Earth Surf. Process. Landf. 2015, 40, 1791-1802. [CrossRef]

53. Hyyppä, J.; Virtanen, J.P.; Jaakkola, A.; Yu, X.; Hyyppä, H.; Liang, X. Feasibility of Google Tango and Kinect for crowdsourcing forestry information. Forests 2017, 9, 6. [CrossRef]

54. Eitel, J.U.; Vierling, L.A.; Magney, T.S. A lightweight, low cost autonomously operating terrestrial laser scanner for quantifying and monitoring ecosystem structural dynamics. Agric. For. Meteorol. 2013, 180, 86-96. [CrossRef]

55. Wilkes, P.; Lau, A.; Disney, M.; Calders, K.; Burt, A.; de Tanago, J.G.; Bartholomeus, H.; Brede, B.; Herold, M. Data acquisition considerations for terrestrial laser scanning of forest plots. Remote Sens. Environ. 2017, 196, 140-153. [CrossRef]

(C) 2019 by the authors. Licensee MDPI, Basel, Switzerland. This article is an open access article distributed under the terms and conditions of the Creative Commons Attribution (CC BY) license (http://creativecommons.org/licenses/by/4.0/). 